\title{
Evolutionary insights into Ptdlns3P signaling through FYVE and PHOX effector proteins from the moss Physcomitrella patens
}

Patricia Agudelo-Romero ${ }^{1,2}$, Ana Margarida Fortes ${ }^{3}$, Trinidad Suárez ${ }^{4,5}$, Hernán Ramiro Lascano $^{6}$ and Laura Saavedra ${ }^{*}$

${ }^{1}$ The UWA Institute of Agriculture, The University of Western Australia, M082 Perth, 6009, Australia and the ARC Centre of Excellence in Plant Energy Biology, The University of Western Australia, M316 Perth, Perth, 6009, Australia.

${ }^{2}$ Current address: Telethon Kids Institute, University of Western Australia, Nedlands, WA, Australia.

${ }^{3}$ Universidade de Lisboa, Faculdade de Ciências, BiolSI - Biosystems \& Integrative Sciences Institute, Campo Grande, 1749-016, Lisboa, Portugal.

${ }^{4}$ Universidad Nacional de Córdoba, Facultad de Ciencias Exactas, Físicas y Naturales, Cátedra de Fisiología Vegetal. Córdoba, Argentina.

${ }^{5}$ Current address: Universidad Nacional de Córdoba, Facultad de Ciencias Químicas, Centro de Investigaciones en Química Biológica de Córdoba. Córdoba, Argentina.

${ }^{6}$ Universidad Nacional de Córdoba, Facultad de Ciencias Exactas, Físicas y Naturales, Cátedra de Fisiología Vegetal, Córdoba, Argentina; CONICET-Instituto de Fisiología y Recursos Genéticos Vegetales, Centro de Investigaciones Agropecuarias, Instituto Nacional de Tecnología Agropecuaria. Córdoba, Argentina.

${ }^{7}$ Universidad Nacional de Córdoba, Facultad de Ciencias Exactas, Físicas y Naturales, Cátedra de Fisiología Vegetal, Córdoba, Argentina; CONICET-Universidad Nacional de Córdoba, Instituto de Investigaciones Biológicas y Tecnológicas (IIByT). Córdoba, Argentina.

*Corresponding author. E-mail: laura.saavedra@conicet.gov.ar

Keywords: Phosphatidylinositol 3-phosphate, Phosphatidylinositol 3,5-bisphosphate, phosphoinositide signaling, PI3K, bryophytes 


\section{ABSTRACT}

Phosphatidylinositol 3-phosphate (Ptdlns3P) is one of the five different phosphoinositides (PPIs) species in plant cells, which regulate several aspects of plant growth and development, as well as responses to biotic and abiotic stresses. The mechanistic insights underlying Ptdlns $3 P$ mode of action, specifically through Ptdlns $3 P$-binding effectors such as FYVE and PHOX proteins have been partially explored in plants with main focus on Arabidopsis thaliana. Additionally, they have been underexplored in other plant organisms such as bryophytes, the earliest diverging group of terrestrial flora.

In this study, we searched for genes coding for FYVE and PHOX domains containing sequences from different photosynthetic organisms in order to gather evolutionary insights on these PPI binding domains, followed by an in silico characterization of the FYVE and PHOX gene family in the moss Physcomitrella patens. Phylogenetic analysis showed that PpFYVE proteins can be grouped in 7 subclasses, with an additional subclass whose FYVE domain was lost during evolution to higher plants. On the other hand, PpPHOX proteins are classified into 5 subclasses. Expression analyses based on RNAseq data together with the analysis of cis-acting regulatory elements and transcription factor binding sites in promoter regions suggest the importance of these proteins in regulating stress responses but mainly developmental processes in $P$. patens. The results provide valuable information and robust candidate genes for future functional analysis aiming to further explore the role of this signaling pathway mainly during growth and development of tip growing cells and during the transition from 2D to 3D growth, which could provide ancestral regulatory players undertaken during plant evolution. 


\section{INTRODUCTION}

Phosphoinositides (PPIs) are eukaryotic signaling phospholipids derivatives of phosphatidylinositol (PI), which control a large number of cellular functions through their role as regulators of membrane dynamics (Schink, Tan, and Stenmark 2016). In plants, PPIs control central aspects of plant growth and development, as well as responses to biotic and abiotic stresses (Gerth et al. 2017). Severe phenotypes have been described using an overexpression or a down-regulation approach for several members of the plant PPImetabolism enzyme network. However, this approach can lead to misleading interpretations of resulting phenotypes and associated PPI-specific biological functions because affecting one member of this network frequently leads to the adjustment of other members of PPImetabolism, in addition to the fact that, some PPI species exist in multiple locations performing different functions.

One of the mechanisms by which PPIs control cellular processes is by their ability to recruit specific phosphoinositide binding protein effectors to membranes in a reversible manner achieved by both, a low to moderate affinity of protein effectors for PPIs, and by PPIs turnover by phosphorylation or dephosphorylation (Moravcevic, Oxley, and Lemmon 2012). Therefore, addressing the role of effectors and downstream targets of PPI regulation will improve our knowledge on PPI-specific functions in plants.

Phosphatidylinositol 3-phosphate (Ptdlns3P) is one of the five different PPI species identified in plant cells and focus of this study. Protein effectors containing a Ptdlns $3 P$-specific binding module are denoted as FYVE and PHOX proteins. FYVE domains, named for the four proteins in which were first identified (Fab1, YOTB, Vac1, EEA) are zinc binding fingers containing $\sim 70$ amino acids, comprising two double-stranded antiparallel $\beta$-sheets and a small C-terminal $\alpha$-helix that are held together by two tetrahedrally- coordinated $\mathrm{Zn}^{2+}$ ions (Kutateladze 2006). This domain is defined by three conserved sequences that form a highly positively charged binding site for Ptdlns $3 P$ : the $W x x D,(R / K)(R / K) H H C R$ and RVC motifs (Kutateladze 2006). Upon binding of the FYVE domain to Ptdlns $3 P$ containing membranes, FYVE domains are able to penetrate into the bilayers through an exposed hydrophobic protrusion known as the membrane insertion loop (MIL). The PHOX domain (also known as $\mathrm{PX}$ ) was originally named for its presence in the $\mathrm{p} 40^{\text {phox }}$ and $\mathrm{p} 47^{\text {phox }}$ subunits of the phagocyte NADPH oxidase complex. Although most PHOX domains bind to Ptdlns $3 P$, affinities for other PPIs and anionic lipids have also been reported. A recently thorough description of the membrane-binding specificities of the human PX domain family resolve four distinct categories of PX domains; including binding specifically to Ptdlns $3 P$, binding other PPIs as well as Ptdlns $3 P$, binding other lipids but not Ptdlns $3 P$, and those that do not appear to bind membrane lipids significantly at all (Chandra et al. 2019). PHOX domains comprise a region of 130 amino acids with a relative weak primary sequence identity but substantial similarity at the level of the three dimensional structure. The overall structure consists of a PI-binding pocket including basic residues, three $\beta$-strands followed by three $\alpha$-helices, and a proline- 
rich loop with the conserved sequence YPxxPxK (Y denotes large aliphatic amino acids $\mathrm{V}, \mathrm{I}, \mathrm{L}, \mathrm{M}$ ) between the first and second helix (Seet and Hong 2006). In most cases, the FYVE and PHOX domains bind weakly to Ptdlns $3 P$ and membrane assembly appear to rely additionally on effector oligomerization to increase avidity of membrane binding, or coincident detection of another membrane molecule, membrane charge or membrane curvature (Schink, Raiborg, and Stenmark 2013).

In silico genome wide analyses have predicted the presence of 15 and 19 FYVE proteins in $A$. thaliana and Oryza sativa, respectively, and 11 PHOX members in both species (Xiao and Shaw 2016, Wywial and Singh 2010, van Leeuwen et al. 2004, Jensen et al. 2001). Up to date, a few FYVE and PHOX proteins have been functionally characterized, mainly in A. thaliana, revealing that Ptdlns $3 P$ is a crucial player in endocytic trafficking, vesicular transport and regulation of autophagy. An example of FYVE-domain proteins are FAB enzymes, which synthesize $\operatorname{Ptd} \operatorname{lns}(3,5) P_{2}$ from $P \operatorname{td} \operatorname{lns} 3 P$, and are essential for endomembrane homeostasis including endocytosis, vacuole formation and vacuolar acidification in A. thaliana (Hirano et al. 2011, Hirano, Munnik, and Sato 2015, 2017, Serrazina, Dias, and Malhó 2014, Bak et al. 2013, Whitley, Hinz, and Doughty 2009). FYVE1/FREE1, another FYVE-domain protein, was shown to participate in several processes such as the regulation of the formation of intraluminal vesicles (ILVs) in prevacuolar compartments/multivesicular bodies (PVCs/MVBs), MVB-mediated sorting and degradation of ubiquitylated membrane proteins, vacuolar protein transport, autophagic degradation, and vacuole biogenesis (Gao et al. 2014, Gao et al. 2015, Barberon et al. 2014, Kolb et al. 2015, Belda-Palazon et al. 2016).

In the case of PHOX domain proteins, the syntaxin family has been the more extensively studied. AtSNX1 function as a sorting endosome from which endocytosed plasma membrane (PM) proteins, such as the Iron-Regulated Transporter1 (IRT1) or the auxin efflux carrier PIN2 and secretory proteins are sorted to diverse destinations (Ivanov et al. 2014, Jaillais et al. 2008, Jaillais et al. 2006, Pourcher et al. 2010). In addition, AtSNX2a and AtSNX2b, have distinct functions in trafficking of storage proteins and plant development (Pourcher et al. 2010), whereas AtEREX, another PHOX-domain protein, was recently suggested as a genuine effector of canonical RAB5s in A. thaliana (Sakurai et al. 2016).

As more species have their complete reference genome sequenced, additional FYVE and PHOX genes can be identified and reveal the biological roles of these gene families. Due to the fact that most available genomes are from flowering plants, covering other rich-species lineages, in particular bryophytes -comprising mosses, liverworts and hornworts- may reveal novel evolutionary paths/functions that have been undertaken during evolution (Rensing et al. 2008, Rensing 2017). The moss Physcomitrella patens is a powerful model system for evolutionary and functional genomics in plants (Rensing et al. 2008, Collonnier et al. 2016, Schaefer and Zrÿd 1997, Bezanilla, Pan, and Quatrano 2003). It belongs to the bryophytes, the earliest diverging group of terrestrial flora. Bryophytes constitute a key group to understand the genetic basis of the critical innovations that allowed green plants to evolve 
from an aquatic ancestor and to adapt to the terrestrial environment (Rensing et al. 2008). In addition, its relatively simple body architecture, an haploid-dominant life cycle, excellent cytology combined with the fact that protonemata and rhizoid cells exhibit polar growth, provide the opportunity to study signal transduction mechanisms at a molecular level, particularly appropriated for processes where vesicle trafficking and secretion are involved (Vidali and Bezanilla 2012, Cove et al. 2006).

We have previously analyzed ${ }^{32} \mathrm{P}$-radiolabeled phospholipids extracted from a suspension culture of $P$. patens protonemal tissue under normal growth conditions and identified a similar PPI composition to that of flowering plants (Saavedra et al. 2009). Ptdlns $3 P$ and Ptdlns $(3,5) P_{2}$ are minor PPIs in $P$. patens, which closely agrees with what is observed in other organisms (Saavedra et al. 2009, Saavedra et al. 2015, Leprince et al. 2014, Meijer et al. 1999). In this study, we performed a genome wide analysis of the FYVE and PHOX gene families in P. patens. Gene structure and protein domain organization of these proteins is well conserved in comparison to higher plants. We performed a phylogenetic analysis and described these proteins in terms of their different domain composition and their potential binding site to Ptdlns3P. Expression analyses based on RNAseq data together with the identification of cis-acting regulatory elements in promoter regions suggest the importance of these proteins particularly regulating developmental processes in $P$. patens. 


\section{MATERIALS AND METHODS}

Identification of FYVE and PHOX genes. Sequences containing FYVE and PHOX domains from 11 plant species (Table S1) namely, Chlamydomonas reinhardtii v5.5, Volvox carterii v2.1, Marchantia polymorpha v3.1, Physcomitrella patens v3.3, Sphagnum fallax v0.5, Selaginella moellendorffii v1.0, Arabidopsis thaliana, Glycine Max Wm82.a2.v1, Vitis Vinifera and Oryza Sativa were retrieved using different approaches in Phytozome v12.1 (https://phytozome.jgi.doe.gov): a BLASTN search against the FYVE or PHOX genes previously described in $A$. thaliana and O. sativa [8-10], a BLASTP search using the FYVE domain amino acid sequence from the mouse hepatocyte growth factor-regulated tyrosine kinase substrate, Hrs [37], and through the BioMart data query tool (https://phytozome.jgi.doe.gov/biomart/martview) using the FYVE and PHOX domain PFAM accession terms PF01363 for FYVE and PF00787 for PHOX, respectively. FYVE and PHOX genes from Klebsormidium nitens v1.1 was retrieved from the Klebsormidium nitens project (http://www.plantmorphogenesis.bio.titech.ac.jp/ algae_genome_project/klebsormidium/klebs ormidium_blast.html). The presence of a FYVE or PHOX domain was further confirmed at the NCBI CCD search domain (https://www.ncbi.nlm.nih.gov/Structure/cdd/wrpsb.cgi), PFAM (http://pfam.xfam.org) and SMART (http://smart.embl-heidelberg.de) databases.

Sequence alignment and phylogenetic analysis. Evolutionary analyses were conducted in MEGA7.0.26 (https://www.megasoftware.net). Multiple sequence alignment was inferred using MUSCLE. The evolutionary history was inferred using the Neighbor-Joining method and the bootstrap consensus tree was inferred from 1000 replicates. The evolutionary distances were computed using the Poisson correction method and are in the units of the number of amino acid substitutions per site.

Chromosomal localization. The genomic localization of the FYVE and PHOX related genes through the 27 chromosomes of Physcomitrella patens was performed by KaryoPloteR R Bioconductor package (Gel and Serra 2017) using plotKaryotype and kpPlotMarkers functions. The custom genome parameter was created with toGRanges function from a BED file with the chromosome sizes.

Promoter analysis. Promoter cis-acting regulatory elements within $1.5 \mathrm{~kb}$ of the upstream sequence from the ATG initial codon of each $P$. patens FYVE and PHOX gene were analyzed with PlantCARE (http://bioinformatics.psb.ugent.be/webtools/plantcare/html/). Analysis of transcription factor binding sites (TFBSs) of the $2.5 \mathrm{~kb}$ upstream sequence region of the initial codon was also performed using the Plant Promoter Analysis Navigator (PlantPAN2.0) $\begin{array}{llll}\text { (http://plantpan2.itps.ncku.edu.tw/), } & \text { and } \quad \text { with }\end{array}$ (http://homer.ucsd.edu/homer/motif/).

Transcript data processing analysis. Raw sequencing data from Physcomitrella patens was survey in the Sequence Read Archive (SRA; https://www.ncbi.nlm.nih.gov/sra) and Gene Expression Omnibus (GEO; https://www.ncbi.nlm.nih.gov/geo/) databases from NCBI. Under transcriptomic data criteria, seven BioProjects were identified, five single-end (PRJNA294412, 
PRJNA153001, PRJNA149079, PRJNA265205) and two pair-end studies (PRJNA266515, PRJNA153109) (Table S10). The fastq files were download using fastq-dump command from

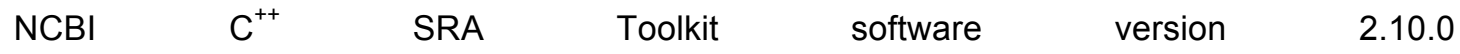
(https://trace.ncbi.nlm.nih.gov/Traces/sra/sra.cgi?cmd=show\&f=software\&m=software\&s=soft ware) and quality control (QC) of raw reads was assessed with FastQC (https://www.bioinformatics.babraham.ac.uk/projects/fastqc/); trimming and adapter removal was performed using Trimmomatic (Bolger, Lohse, and Usadel 2014). Resulting reads were aligned to Physcomitrella patens ( $P$. patens 318 v3.3) reference genome (https://phytozome.jgi.doe.gov/pz/portal.html\#!info?alias=Org_Ppatens) using Kallisto (Bray et al. 2016). Mean quality scores report and summary statistics of read length, number of reads and read mapping are provided in Figure S3. Gene expression profiling was performed using edgeR (Robinson, McCarthy, and Smyth 2010) and limma (Ritchie et al. 2015) Bioconductor packages. The counts matrix obtained from Kallisto was read in edgeR, and the $\log _{2}$ transcripts per million (logTPM) was obtained and normalized using the trimmed mean of M values (TMM) method (Robinson, McCarthy, and Smyth 2010). Data were then filtered considering a fold change a $\mathrm{FC}>|1.5|$.

Network interaction of promoters. A co-expression network was built using the relationship of the gene vs known motif analysis (Homer v4.977; http://homer.ucsd.edu/homer/motif/) for PpFYVE and PpPHOX (Table S7 and Table S8). The gene and motif interaction matrixes were mapped employing Cytoscape 3.6.1 software (Shannon et al. 2003). Node table was generated using Molecular Complex Detection (MCODE) App (Bader and Hogue 2003) and nodes with more than four connections were depicted (Table S9). 


\section{RESULTS}

\section{Structural annotation of PpFYVE and PpPHOX genes}

A search for genes coding for FYVE and PHOX domain proteins was performed in different photosynthetic organisms (Chlorophytes, Charophytes, Bryophytes, Lycophytes and Angiosperms) using different approaches (Materials \& Methods). As a result, 136 FYVE and 88 PHOX domain-containing proteins were used in this study (Table S1). In the case of $P$. patens 13 and 9 FYVE and PHOX domain-containing proteins respectively, were identified in a total of 35,307 predicted protein-coding genes from the $P$. patens genome (Figure 1). The alternative splice variants, which shared a common genome locus and coding sequences, were tightly related to each other (Table S2 and S3), and therefore we selected the longer of the sequence variants for further analyses. PpFYVE and PpPHOX genes are dispersed throughout the $P$. patens genome, being located on different chromosomes (Figure 1 ) and the protein members of each subfamily have a conserved modular structure compared to their orthologs from other plant species (Figure 2).

\section{$P$. patens FYVE proteins exhibit a similar modular structure in comparison to FYVE proteins from higher plants, but together with Charophytes exhibit an additional group.}

A phylogenetic analysis of PpFYVE proteins from the different organisms, as mentioned above resulted into 6 subfamilies previously described (Class I-VI) and an additional group (Class VII) with members only present in Charophytes and mosses (Figure 3). Chlorophytes exhibit very few FYVE proteins, one protein for Class II in Chlamydomonas reinhardtii and one protein for each Class II and I in Volvox carterii. Interestingly, Klebsormidium nitens, a filamentous terrestrial algae belonging to the Charophytes, which are widely accepted as the ancestors of current terrestrial plants exhibit one member for each of the seven classes of FYVE proteins identified in mosses. As soon as plants evolved to more complex forms the number of proteins for the different classes of FYVE proteins become in general larger, best exemplified by Class $V$, whereas the FYVE domain present in members of Class VII is lost.

Class I FYVE is represented by FAB kinases and has 2 members in $P$. patens, PpFAB1 and PpFAB2. FAB enzymes in plants, known as Fab1p in yeast and PIKfyve in mammals, are phosphatidylinositol 3-phosphate 5-kinases that synthesize Ptdlns $(3,5) P_{2}$ from Ptdlns $3 P$. Both PpFABs cluster together and share $81 \%$ similarity. They harbor three conserved domains: the N-terminal FYVE domain necessary for binding to Ptdlns $3 P$ containing membranes, a Cpn60_TCP1 (HSP chaperonin_T complex1) homology domain and a C-terminal kinase domain (Mueller-Roeber and Pical 2002), in accordance with the description of $F A B s$ (Figure 2). FAB proteins in plants have additional members lacking a FYVE domain. The single $F A B$ protein present in $C$. reinhardtii lacks a FYVE domain, whereas $P$. patens and $A$. thaliana have one (Pp3c17_4720) and two members AtFAB1C (At1g71010) and AtFAB1D (At1g34260), respectively. The class II FYVE is represented by a 
single protein in P. patens, PpFYVE2 and consists of two, three and four members in $A$. thaliana, V. vinifera and $O$. sativa, respectively. Members of this family contain a FYVE domain and a C-terminal SYLF domain (also called DUF500). The SYLF domain is named "SYLF" on the basis of its representative members (SH3YL1, Ysc84p/Lsb4p, Lsb3p, and plant FYVE protein), and comprises a segment of $\approx 220$ residues shown to be a lipid-binding module. Both the FYVE and the SYLF domain of AtFYVE2 also referred as CFS1 (CELL DEATH RELATED ENDOSOMAL FYVE/SYLF PROTEIN 1), were shown to bind to Ptdlns3P (Sutipatanasomboon et al. 2017). A subgroup of proteins from class II including PpFYVE2 and AtFYVE2, exhibit a $\mathrm{P}(\mathrm{S} / \mathrm{T}) \mathrm{XP}$ motif which is known from yeast and mammals to mediate binding to the Vps23/TSG101 subunit of the endosomal sorting complex required for transport (ESCRT)-I. AtFYVE2 is the only characterized protein from this class, and is involved in fusion events between autophagosomes and ESCRT-positive late endosomes (LEs), affecting autophagosome degradation and protein homeostasis (Sutipatanasomboon et al. 2017). The class III FYVE is represented by a single member in all species studied, except for G. max which has two members. P. patens PpFYVE4, contains only a FYVE domain close to the $\mathrm{N}$-terminus and up to date no functional role has been reported for these proteins. Class IV together with Class I are the best characterized FYVE proteins in A. thaliana. Class IV FYVE harbors one member in $P$. patens (PpFYVE1) with only a FYVE domain localized close to the C-terminus. FYVE1 has no homologs in animal cells, and in A. thaliana the homolog gene product named FREE1/FYVE1 binds to Ptdlns3P through its FYVE domain and is involved in the degradation of ubiquitin-dependent membrane proteins, vacuolar transport, autophagy and vacuole biogenesis, showing FYVE1 as a central component of the traffic machinery, as stated previously (Gao et al. 2014, Barberon et al. 2014).

The largest subgroup of proteins with a FYVE domain in higher plants is Class V. It is absent in Chlorophytes, has one member in K. nitens and M. polymorpha, 3 members in $P$. patens (PpPRAF1-3) reaching to 9 members in $A$. thaliana and $O$. sativa. The three proteins present in $P$. patens have closer similarity to AtPRAF8 and AtPRAF9 (59-60\% identity). Proteins from this group are characterized by two phosphoinositide binding domains, the $\mathrm{PH}$ (plekstrin homology) and FYVE domains, several repetitions of the RCC1 (regulator of chromosome condensation 1) motif, and a BRX (Brevis Radix) domain. PH domains bind various PPIs, but preferentially to Ptdlns $(4,5) P_{2}$, which was confirmed in vitro for the recombinant GST$\mathrm{PH}_{\text {AtPRAF4 }}$ (Jensen et al. 2001). Interestingly, all FYVE domains of PRAF proteins analyzed exhibit two important substitutions in the basic $(R / K)_{1}(R / K) H H C R_{6}$ motif, His4 and Arg6 which are components of the binding pocket that determines the specificity for binding of Ptdlns $3 P$ (Gaullier et al. 2000) are substituted by asparagine and tyrosine (Supplemental figure 1). The RCC1 motif is present in several proteins in P. patens and in other organisms, it was reported as a versatile domain which may perform different functions, including guanine nucleotide exchange on small GTP-binding proteins, enzyme inhibition, or interaction with proteins and lipids (Hadjebi et al. 2008). A guanine nucleotide exchange activity has been demonstrated for AtPRAF1 (Jensen et al. 2001). The BRX motif is a protein-protein interaction domain, and 
it is present as tandem repeats in AtBRX, a transcription factor that regulates cell growth (Beuchat et al. 2010, Mouchel, Briggs, and Hardtke 2004). A FYVE domain followed by an ankyrin domain characterizes the modular structure of class VI FYVE proteins. Interestingly, this class is absent in Chlorophytes and in $A$. thaliana although is present in the other organisms analyzed in this study. The ankyrin domain mediates protein-protein interactions, but no functional role of this subgroup has been addressed yet.

Finally, members of the last class of FYVE-domain proteins, class VII from the organisms analyzed were only present in K. nitens, and in the mosses P. patens (PpALFY1-4) and S. fallax. These proteins exhibit a similar domain structure to the mammalian protein ALFY (autophagy-linked FYVE protein), which is required for degradation of protein aggregates by autophagy (aggrephagy) (Simonsen et al. 2004). Proteins belonging to this subgroup exhibit in addition to the FYVE domain located close to the C-terminus and a PH domain followed by a BEACH domain and a tandem repeat of WD domains. Interestingly, proteins lacking the FYVE domain but with a similar modular structure are present in $M$. polymorfa, $S$. moellendorffii and all the angiosperms analyzed in this study, suggesting that this domain was lost during higher plants evolution. The BEACH domain consists of $\sim 280$ amino acids and is found in eukaryotic proteins involved in vesicle trafficking, yet the function of this domain is unknown. The WxxD, RRHHCR and RVC motifs are less conserved in PpALFYs, any of the four proteins conserved the WxxD motif, and PpALFY 1-2 are the two members with a conserved RRHHCR and RVC motifs (Supplemental Fig.1).

\section{$P$. patens $\mathrm{PHOX}$ proteins are classified into 5 groups, share a similar modular structure} in comparison with PHOX proteins from higher plants but lack PLD $\zeta$ with this domain

The phylogenetic analysis of PHOX proteins from the Chlorophytes, Charophytes, Bryophytes, Lycophytes and Angiosperms analyzed, grouped these proteins into five different groups named Class I-V (Figure 2 and Figure 4). Members from P. patens clustered with the subfamilies previously described for $A$. thaliana with the exception of class $V$, which are phospholipases D type Zeta (van Leeuwen et al. 2004).

The proteins belonging to classes I and IV are represented by the SNX (Sorting Nexin) protein family. Several SNXs are components of the retromer complex, which is involved in the recycling/retrograde transport of VSRs (Vacuolar Sorting Receptors) and PM proteins from endosomes to the trans Golgi network (TGN) (Heucken and Ivanov 2018). Class I is composed of two members: PpSXN1 which shares 49\% identity with AtSNX1 (AT5G06140), and PpSNX2 which clusters with AtSNX2a (AT5G58440) and AtSNX2b (AT5G07120) and shares with them $56.89 \%$ and $55.40 \%$ identity, respectively. In addition to the PHOX domain, class I proteins exhibit a BAR (Bin-Amphiphysin-Rvs) domain at their C-terminal region which enables dimerization and binding to curved membranes. The class II is represented by PpPX1 and PpPX2, and exhibit only a PHOX domain positioned close to the N-terminus. $A$. thaliana has three members within this group, AtPX1/EREL1 (AT4G32160), AtPX2/EREX (AT3G15920) and AtPX3/EREL2 (AT2G25350). The AtEREX (Endosomal Rab Effector with 
PX-domain) protein has been suggested as a genuine effector of canonical RAB5s mediating vacuolar trafficking (Sakurai et al. 2016). Members of class III are single proteins in all species analyzed with exception of G. max, and are represented by PpSXN5 in $P$. patens. These proteins exhibit a PHOX and a C-terminal RING9 domain, but none physiological role has been assigned to this group yet. Proteins from class IV in P. patens (PpSNX4a-d), contain a PXA (PHOX-associated) domain, the PHOX domain and a conserved $\mathrm{C}$-terminal domain, referred to as PXC domain. A. thaliana and $P$. patens PHOX domains from this group have homology to human SNX19 PHOX domains, but the function of these proteins in plants remains unknown. Class $V$ contains members of phospholipase $D$ type Zeta (PLD AT3G16785 and AT3G05630). By using the BioMart data query tool with the PFAM accession term for PHOX domain proteins in P. patens none PLD sequences were obtained. Therefore, protein sequences with a high percentage of identity to AtPLD $\zeta$ were retrieved, resulting two sequences Pp3c13_3440V3.1 and Pp3c12_3620V3.1, which were further analyzed. None of them scored a PHOX domain associated with a significant $E$-value as noticed for PHOX domains from HsPLD1 and HsPLD2 (Supplemental Table 4). Thus, P. patens PLD sequences were excluded from the analysis.

Additionaly, an in silico analysis was performed to search if PHOX domains from $P$. patens exhibit the amino acids required for the binding to Ptdlns3P. Bravo et al. (Bravo et al. 2001) have previously described the crystal structure of the $\mathrm{p} 40^{\text {phox }} \mathrm{PHOX}$ domain bound to Ptdlns3P, denoting the four key residues within this domain, Arg58, Tyr/Phe59, Lys92 and Arg105 (numbers corresponding to $\mathrm{p} 40^{\text {phox }} \mathrm{PHOX}$ as reference) that determine specificity and are required for binding to Ptdlns $3 P$. Analysis of these sites in the PpPHOX family showed that all members of Class I and II harbor these four key residues (Supplemental Figure 2), suggesting that these domains could bind Ptdlns $3 P$ in vivo. The exception to this, was exhibited by proteins of Classes III and IV, PpSNX4a-d and PpSNX5, where Lys92 is substituted by arginine, but still conserved the positive charge.

\section{Cis-acting regulatory elements in promoter regions}

Analysis of cis-regulatory elements from the PpFYVE and PpPHOX promoter regions was performed using the PlantCARE (Table S5), PlantPAN database (Table S6) and Homer software (Tables S7 and S8). PpFYVE and PpPHOX promoters contain in addition to the core cis-elements, including the TATA box and CAAT box motifs presented in all promoter regions, several regulatory motifs identified and associated with light regulation (BOX I, BOX 4, ACE, MRE, LAMP), low temperature and drought responses (LTR, MBS), defense and stress responses (e.g. TC-rich repeats), hormonal regulation such as salicylic acid (e.g TCAelement), methyl jasmonate (e.g CGTCA-motif, TGACG-motif), auxin (AuxRR-core, TGAelement), abscisic acid (ABRE), and regulatory motifs related to developmental processes/ cell differentiation (HD-Zip 1, HD-Zip 2). A transcription factor (TF) survey of binding sites was performed to FYVE and PHOX genes using the Homer platform, and elements with a score higher than 10 were used for further analysis. Interestingly, the classes of TFs binding sites 
identified in the promoter region of various members from PpFYVE and PpPHOX genes were those associated mainly with plant growth and developmental processes and with stress responses, such as ARID, ABI3VP1, C2C2 dof, C2H2, NAC, G2 like, Homeobox (HD-ZIP), Myb (Figure 5 and Figure 6). Several TFs binding sites were present in promoters from a subset of both PpFYVE and PpHOX genes including ATHMGB15 (ARID, AT1G04880), AT2G40260 (G2like), ATHB13, ATBH51, ATBH53 and HGDI (Homebox), AT5G60130 (ABI3VP1), IDD5(C2H2) and At4g38000 (C2C2dof) (Table S9).

\section{Expression analysis of $P$. patens FYVE and $P H O X$ genes}

\section{Gene expression during development}

The transcriptional signature of $P p F Y V E$ and $P p P H O X$ was studied among different developmental stages of $P$. patens life cycle and under abiotic stress conditions (Table S8 see Materials and Methods). As it is briefly described herein, $P$. patens life cycle is dominated by a photoautotrophic haploid gametophytic generation, that supports an ephemeral heterotrophic diploid sporophyte (Cove et al. 2006). P. patens gametophyte consists of a juvenile filamentous protonemata and the leafy adult stage (gametophore or leafy shoot). Protonemata cells, chloronemata and caulonemata, develop by apical growth and cell division of apical and subapical cells. Chloronemata are the first cells to emerge from the spore or protoplast, whereas caulonemata develop by progressive differentiation of chloronemal apical cells in response to environmental signals such as light and auxin. Caulonema cells form side branch initial cells of which a few become buds (gametophore apical cells), which are meristematic and develop into an adult gametophore comprising a photosynthetic nonvascularized stem, leaves, the reproductive organs, supported by the development of rhizoids. Protonemata and rhizoids are cell types that exhibit polar growth.

During the different stages of moss development, several PpFYVE and PpPHOX were modulated revealing the importance of these proteins in regulating developmental processes (Figure 7). The data used for this study comprises different time points during protoplast regeneration $(24 \mathrm{~h}, 48 \mathrm{~h}$ and $72 \mathrm{~h}$ ) that were compared against $0 \mathrm{~h}$. Within the first $24 \mathrm{~h}$ of culture a new cell wall is developed, new polar axes are re-established within $48 \mathrm{~h}$ when reprogramming into stem cells occurred, and after $72 \mathrm{~h}$ protoplasts divided asymmetrically leading to chloronemata that contained two to three cells (Xiao et al. 2012). During this period of time several FYVE genes were down-regulated, namely PpFAB2, PpFYVE4, PpFYVE1, PpALFY1 and PpPRAF3 (Figure 5A). Also, these genes were downregulated in the comparison of chloronema vs protoplast in the expression data from the eFP Physcomitrella Browser (Ortiz-Ramírez et al. 2016). In juvenile protonemata PpFAB1-2, $P p P R A F 2, P p A L F Y 3$ were up-regulated in the comparison caulonemata vs chloronemata, whereas PpFYVE4 and PpALFY3 along with PpFYVE1 were up-regulated in the bud vs tip comparison. PpPRAF3 was down-regulated at several stages of development $(3,14,24$ and 30 d), while PpALFY3 was up-regulated at 24 days, time point when buds had formed from protonemal filaments and represents initiation of leafy shoots and at $30 \mathrm{~d}$ (Xiao et al. 2011). 
PpALFY1 was the only FYVE gene up-regulated when gametophore was compared to the whole plant, and both PpALFY4 and PpFYVE5 were up-regulated in the young sporophyte comparing to the whole plant. The expression patterns observed at 24 and 30 days compared to 3 days and chloronemata, also suggest that a group FYVE genes (PpPRAF2, PpALFY3, $P$ PFYVE4) may acquire a role at latter stages of moss development, during the two dimensional (2D) to three dimensional (3D) growth transition in a moss.

In the case of the expression of PHOX genes, PpPX2 together with PpSNX1, $P p S N X 4 a$ and $P p S N X 4 d$ were up-regulated at $24 \mathrm{~h}$ vs $0 \mathrm{~h}$ of protoplast regeneration (Figure 5B). However, expression of PpPX2, PpSNX1 together with PpSNX5 and PpSXN4c decreased at latter time points of this process ( $72 \mathrm{~h}$ compared to $0 \mathrm{~h}$ ) when chloronema development was initiated. During protonemata development the syntaxins PpSNX2, PpSNX5 and $P p P X 2$ were up-regulated in caulonemata compared to chloronemata. PpSNX4d, $P p S N X 2$ were up-regulated in the comparison of bud vs whole plant or tip. This result is reinforced by the fact that these genes are also up-regulated at 24 days (stage where buds had developed from protonemal filaments) compared to chloronemata. Several PHOX genes were down-regulated in the comparison chloronemata against caulonemata (development stage 14 days composed of protonemata where chloronemal cells were about twice as numerous as caulonemal cells), namely PpSNX4b, PpSNX4c and PpSNX5. Additionally, PpSNX4c presents a strong down-regulation in several cell types but is ipregulated in the developmental stage of 24 days rich in caulonemata. PpSNX4b and PpSNX4d were up-regulated in the gametophore comparing to the whole plant and $P p P X 2$ was up-regulated in the young sporophyte comparing to the whole plant.

\section{Gene expression upon abiotic stress}

Expression signature under abiotic stress of PpFYVE and PpPHOX revealed that the majority of their transcripts were down-regulated upon the stresses imposed by $A B A$, cold, salt, light and drought treatments (Figure 8). As example, PpFAB1, PpALFY1-3, PpPRAF2 and PpFYVE5 were down-regulated in drought conditions (30 min) but up-regulated in the anr (ABA NON-RESPONSIVE) mutant (Figure 6A), which fail to express dehydration tolerance-associated genes in response to drought, $A B A$, or osmotic stress and do not acquire ABA-dependent desiccation tolerance (Stevenson et al. 2016). Additionally, PpALFY1,2 and 4 genes were down-regulated upon salt treatment. While, PpSXN4c was the only $P H O X$ gene up-regulated during $A B A$, cold and salt treatments after 30 min (Figure 8B). 


\section{DISCUSSION}

Ptdlns3P is synthesized from PI by type III PI3Ks [(phosphatidylinositol 3-kinase, also known as VPS34 (Vacuolar Protein Sorting 34)]; the only type of PI3K present in plant genomes. Either by silencing the PI3K gene, or by using the pharmacological type III PI3K inhibitors, it was revealed that Ptdlns $3 P$ is involved in several biological processes such as the polar growth of root hairs (Lee, Bak, et al. 2008), pollen development (Lee, Kim, et al. 2008), auxin induced root gravitropism (Joo et al. 2005) and seed germination (Liu, Zhou, and Xing 2012). Under stress conditions, Ptdlns $3 P$ is required for stomatal closure (Park et al. 2003). In response to salt stress, it is necessary for endocytosis of PM and intracellular ROS production within endosomes (Leshem, Seri, and Levine 2007), and regulates proline metabolism (Leprince et al. 2014). Furthermore, it has been shown to be essential in the early stages of mutualistic interactions of legumes with beneficial microorganisms (PelegGrossman, Volpin, and Levine 2007, Robert et al. 2018, Estrada-Navarrete et al. 2016), as well as in the pathogenic responses (Kale et al. 2010). However, the mechanistic insights underlying Ptdlns $3 P$ mode of action, specifically downstream targets of Ptdlns $3 P$, still remains partially unexplored in plants. Moreover, $\operatorname{Ptd} \operatorname{lns} 3 P$ is the precursor of $\operatorname{Ptd} \operatorname{lns}(3,5) P_{2}$, which has also important roles in membrane trafficking (Hirano, Munnik, and Sato 2017), thus the importance to distinguish between the roles attributed to Ptdlns $3 P$ or due to an inability of cells to produce Ptdlns $(3,5) P_{2}$ due to the lack of its precursor. Therefore, unraveling the functional role of Ptdlns $3 P$ effectors such as FYVE and PHOX-domain proteins would provide advances in this area.

\section{Evolution of FYVE and PHOX domains in Viridiplantae}

Previous studies have shown that FYVE and PHOX domains are distributed across various eukaryotic lineages, but with a distinct selectivity. While Fungi and Metazoa groups have a higher occurrence of the PHOX domain, Streptophyta of Viridiplantae, exhibit an opposite trend, with a higher number of FYVE domain proteins (Banerjee, Basu, and Sarkar 2010). Phylogenetic analysis performed in this study divided the FYVE gene family into 6 subfamilies previously described (Class I-VI), and an additional group (Class VII). Members of the Chlorophytes such as C. reinhardtii and V. carterii have only Class II and Class I/II FYVE proteins, respectively (Figure 3), whereas other members such as Ostrococcus lucimarinus and Ostreococcus tauri do not encode any FYVE proteins (Banerjee, Basu, and Sarkar 2010). Class I (FABs), are highly conserved proteins from yeast to mammals and plants, and members from this class conserved all the canonical ligand-binding site consensus sequence of RRHHCR (Supplemental Fig. 1). Interestingly, although C. reinhardtii lack FAB proteins with a FYVE domain, it harbors the capacity to synthetize Ptdlns(3,5) $P_{2}$ (Meijer et al. 1999), and in similar fashion, in vitro activity assays using heterologous recombinant AtFAB1C-GST, which lacks a FYVE domain shown its ability to synthetize Ptdlns $(3,5) P_{2}$ from Ptdlns $3 P$ (Bak et al. 2013). This suggests that other amino acids residues different from those of the FYVE 
domain are important/required for substrate recognition and specificity for the catalytic activity of these proteins.

The class II of FYVE proteins is present in all species analyzed. The first arginine in the consensus sequence $\mathrm{R}_{1} \mathrm{RHHCR}$ has a substitution for glycine or serine (Supplemental Fig. 1), but in $A$. thaliana it maintains the ability to bind Ptdlns $3 P$, together with the SYLF domain exhibited by these proteins (Sutipatanasomboon et al. 2017). A subgroup of proteins from class II already present in Chlorophytes which includes PpFYVE2, harbor a P(S/T)XP motif, which mediate binding to the Vps23/TSG101 subunit of ESCRT-I. AtFYVE2, the A. thaliana ortholog of PpFYVE2 acts as an autophagy regulator and repressor of cell death, it binds to the ECL component of ESCRT-I LEs and is involved in autophagosome turnover (Sutipatanasomboon et al. 2017).

Through the analysis performed in $K$. nitens, our results indicate that the seven classes of FYVE domain proteins are present in Charophytes (Figure 3), the closest living relatives of land plants. The data suggest that different to Classes I and II, which evolved earlier, Ptdlns3P signaling through Classes III-VII is involved in processes necessary for terrestrialization, ej. acquisition of adaptive mechanisms to cope to abiotic stresses and/or the evolution to more complex body sizes through cellular differentiation. A suitable example in this regard, is the Class $\vee$ (PRAFs), which are plant-specific proteins, characterized apart from the FYVE domain, by a PH, RCC1 and BRX domains. The single functional report of these proteins showed its requirement for normal root and nodule development in $M$. truncatula (Hopkins et al. 2014). Interestingly, the BRX domain of AtPRAF4 (At1g76950) was shown to interact with BRX proteins, which are only found in multicellular plants, and control the extent of cell proliferation and elongation in the growth zone of the root tip (Briggs, Mouchel, and Hardtke 2006). PRAF proteins exhibit another deviation of the $\mathrm{RRHH}_{4} \mathrm{CR}_{6}$ canonical motif, where asparagine and tyrosine substitute His4 and Arg6 (Supplemental Fig. 1). Although a recombinant $6 X \mathrm{XHis}-\mathrm{FYVE}_{\mathrm{AtPRAF} 4}$ exhibit binding towards Ptdlns $3 P$, a double mutant GST-FYVE ${ }_{\text {AtPRAF4-N658H,Y660R }}$ has an increased affinity to Ptdlns3P, highlighting the importance of this residues for the specific binding (Gaullier et al. 2000, Jensen et al. 2001). Yet, the role of FYVE domain in these proteins is unknown.

Class VII proteins were only found in $K$. nitens and in $P$. patens. Although the proteins with a modular structure of $\mathrm{PH}, \mathrm{BEACH}$ and WD40 domains are conserved through land plant evolution, the FYVE domain is absent in these proteins in the liverwort M. polymorpha and in tracheophytes, suggesting that its function was not further essential. Interestingly, the FYVE domain of PpALFYs exhibits a low degree of conservation in comparison to the canonical FYVE sequence (Supplemental Fig. 1).

Phylogenetic analysis of $\mathrm{PHOX}$ proteins clustered these proteins into five different groups, Class I-V. Different to what was observed for FYVE proteins, PHOX-domain proteins for classes I, II and IV, with exception for class III and V (PLDל), are already present in Chlorophytes, suggesting that these proteins are involved in conserved processes of eukaryotic cells through evolution, reported as both cargo adaptors in cell trafficking and 
scaffolds regulating signal transduction.

The subfamily of Class I proteins possessing a C-terminal BAR domain are components of the retromer, a key protein complex involved in cargo recycling and retrograde transport. Different to what observed in mammalian cells, SNXs are dispensable for membrane binding and function of the retromer complex in A. thaliana (Pourcher et al. 2010). Components of the core subunit of the retromer (Vps35p, Vps29p and Vps26p) can work with or independently of SNXs in the trafficking of seed storage proteins, suggesting distinct functions for subcomplexes of the plant retromer, or that these proteins perform additional functions independently of the it (Heucken and Ivanov 2018, Pourcher et al. 2010). A functional role for proteins from class II was recently described in A. thaliana, with AtEREX as a genuine effector of canonical RAB5s and the two homologs (AtEREL1 and AtEREL2) play partially redundant functions in the transport of seed storage proteins (Sakurai et al. 2016). The role of proteins from class III and IV is unknown. Interestingly, proteins from class III have in addition to the PHOX domain a C-terminal RING9-type Zn-finger domain, but this modular arrangement has not been found in other organisms, suggesting plant-specific functions.

All PHOX domains from $A$. thaliana and $P$. patens studied exhibit the four residues $\mathrm{R}_{58} \mathrm{Y} / \mathrm{F}_{59} \mathrm{~K}_{92} \mathrm{R}_{105}$ (with $\mathrm{p} 40^{\text {phox }}$ as reference (Bravo et al. 2001)), critical for Ptdlns3P recognition conserved, with exception of members form Classes III and IV, where Lys92 is substituted by another positively charged amino acid, arginine. The PHOX domain specificity towards PPIs has been tested for AtSNX2b, AtEREX (At3g15920) and AtSNX1. AtSNX2b and AtEREX binds to Ptdlns3P in vitro, and this association with the former is required for the localization of AtSNX2b to punctate structures in vivo, identified as the trans-Golgi network, prevacuolar compartment and endosomes (Phan, Kim, and Bassham 2008). In the case of AtSNX1, although it binds to Ptdlns3P, it prefers Ptdlns $(3,5) \mathrm{P}_{2}$ in planta (Pourcher et al. 2010, Hirano, Munnik, and Sato 2015).

\section{PpFYVE and PpPHOX promoters contain several TFs binding sites involved in development of pollen and root growth}

Analysis of putative TFs binding sites in PpFYVE and PpPHOX promoters showed groups of genes with same TF binding sites with interesting functions in growth and development. For example, PpSNX1, PpSNX2, PpSNX4c, PpPX1 have all sites for homeodomain leucine zipper class I HB13, HB53 and HB51. In A. thaliana HB13 is crucial for pollen germination (Capella, Ribone, and Chan 2015), HB53 suggested to have a regulatory role in auxin/cytokinin signaling during root development (Son et al. 2005), and HB51 (LMI1) is a meristem identity regulator (Saddic et al. 2006). Interestingly, these three TF binding sites were also observed in promoters of several PpFYVE as PpPRAF2-3, PpALFY1-4 and PpFYVE4. PpSNX1, PpSNX4c, PpPX1 cluster together in the heatmap of developmental stages in $P$. patens inviting to explore (Figure 7B) the role of these genes in protonemata and rhizoids apical growth and during the development of meristematic buds. Another TF binding site observed in promoters from FYVE and PHOX genes is HDG1, which belongs to the HD- 
ZIP IV family and promote cell differentiation (Horstman et al. 2015), in addition to BLUEJAY and RAVEN which are part of the network regulated by BLJUEJAY, JACKDAW, SACRECROW and SHORT-ROOT to regulate root tissue patterning through cell lineage specification and asymmetric cell division (Moreno-Risueno et al. 2015).

\section{PpFYVEs are specifically expressed in different developmental stages of $\boldsymbol{P}$. patens,} and several members are up-regulated in caulonemata and gametophore apical cells

FYVE and PHOX genes showed different expression patterns across the developmental stages of $P$. patens, but until now none of these genes have been characterized in $P$. patens with exception of PpFABs, where silencing these genes impaired protonema polarized growth (van Gisbergen et al. 2012). Aside from Class I (FABs), PpFYVE classes with additional members as Classes $\mathrm{V}$ and VII did not exhibit a subclass-specific expression pattern, suggesting gene-specific function or localization regardless the phylogenetic class. PpFABs are up-regulated in caulonemal and bud cells, whose differentiation and formation, respectively, is stimulated by auxin (Thelander, Landberg, and Sundberg 2018). Interestingly, pleiotropic auxin-signaling phenotypes are observed in Atfab1a/b mutants due to a mislocalization of auxin transporters, as a result of the impairment of the recycling process of these proteins between the PM and endosomal compartments (Hirano et al. 2011). Furthermore, synthesis of Ptdlns $(3,5) P_{2}$, FABs synthesis product, on LEs is necessary as a scaffold for the recruitment of LE effector proteins for endosome maturation, giving the identity of LE necessary for the proper PIN trafficking (Hirano, Munnik, and Sato 2015). In close relation to this role for organelle maturation/acidification, synthesis of $\mathrm{PI}(3,5) P_{2}$ by $F A B s$ is necessary for vacuolar acidification in pollen tubes (Serrazina, Dias, and Malhó 2014), and in guard cells during stomatal closure induced by ABA in $A$. thaliana (Bak et al. 2013). The tonoplast proton transporter V-PPase was suggested as a putative effector in the control of vacuolar acidification since it binds $P \operatorname{tdlns}(3,5) P_{2}$ in vitro (Bak et al. 2013). Another potential effector of Ptdlns $(3,5) P_{2}$ is the V-ATPase, which is critical to ensure efficient phagosomal acidification in the defense against pathogenic microbes (Buckley et al. 2019). It would be of particular interest to evaluate if FABs have a role in the autophagic process in plant cells, in particular related to achieve/maintain the required acidic environment in autophagic vesicles and in the lytic vacuole for proper functioning.

PpFYVE1, PpPRAF2 and PpALFY3 are PpFYVEs that were also up-regulated in buds and caulonemal cells. Caulonema are fast growing cells, serve to colonize new substrates and are induced under nutrient deficit. Thus, genes involved in vesicular trafficking and autophagy could acquire an important role to sustain rapid growth and maintain growth under stress conditions. In A. thaliana, FYVE1 (FREE1) is ubiquitously expressed and has important roles in intracellular trafficking and autophagy. AtFYVE1 binds to Ptdlns $3 P$ through its FYVE domain and to ubiquitin, and interacts with Vps23 allowing its incorporation into the ESCRT-I complex required for vacuolar sorting of ubiquitinated membrane proteins (Gao et al. 2014). 
Also, it also interacts with SH3P2 and associates with the PI3K complex to regulate the autophagic degradation in plants (Zhuang and Jiang 2014).

PpPRAF2 is up-regulated in caulonema but also in buds (gametophore apical cells) which are meristematic cells. A M. truncatula PRAF, MtZR1, with $51,4 \%$ similarity with PpPRAF2, is mainly expressed in the root tip, the meristems of emerging lateral roots and during nodule development (Hopkins et al. 2014). Additionally MtZR1 has been suggested to be involved in the development of root and nodules (Hopkins et al. 2014). Several lines of evidence indicate that a root-like developmental program is operational in the nodule meristem, where WOX5 and PLT1-4 are essential regulators (Franssen et al. 2015). Interestingly, analysis of PpPRAF2 promoter reveals binding sites for AP2-type TFs such as PLT1 and AIL7 (Supplemental table 7), which are essential regulators of gametophore apical cells in $P$. patens (Aoyama et al. 2012), raising the possibility that PpPRAF2 could have a role to promote the acquisition of the 3D fate necessary for leafy shoot formation.

PpALFY3 belongs to proteins from class VII. A mammalian protein with a similar domain structure to class VII is ALFY (Autophagy Linked FYVE protein), a large scaffolding protein required for degradation of protein aggregates by selective macroautophagy (Filimonenko et al. 2010). ALFY interacts directly with the autophagy receptor p62 through its $\mathrm{PH}$ and $\mathrm{BEACH}$ domains, to Atg5 through the WD40 domain and with Ptdlns3P-containing membranes through its FYVE domain (Filimonenko et al. 2010, Simonsen et al. 2004).

\section{PpSNXs are PHOX members mainly express during development of $P$. patens}

PpSNX1, PpSNX2, PpSNX4c and PpPX2 were PHOX genes mainly up-regulated in caulonemata and buds. Orthologs of PpSNX1 and PpSNX2 in A. thaliana, AtSNX1, AtSNX2a and AtSNX2b, are components of the SNX subcomplex of the retromer, but the triple mutant in $A$. thaliana displays only minor developmental defects under standard growth conditions (Pourcher et al. 2010). However, it has been postulated that SNX proteins may represent a potential stress-response trafficking module in plant cells, required upon an enhanced demand of specific protein recycling (Brumbarova and Ivanov 2016). Co-localization analyses showed that AtSNX1 positive-endosomes are involved in the trafficking and recycling of several PM proteins such as PIN2 efflux auxin carrier under high temperatures (Jaillais et al. 2006, Hanzawa et al. 2013), or the iron transporter IRT1 in the regulation of iron homeostasis upon iron deficiency (Ivanov et al. 2014). Homologs of PpSNX4s in A. thaliana have also been highly expressed in young tissue, namely young seedlings, in young leaves, root tips, and developing embryos, and AtEREX1 is involved in the biosynthetic trafficking to vacuoles as an effector of RAB5 (Sakurai et al. 2016). So far, the role of these proteins in P. patens is unknown.

PpFYVE and PpPHOX exhibit subtle changes at the transcriptional level upon abiotic stresses suggesting a posttranslational control 
Transcriptional changes in response to abiotic stresses for PpFYVE and PpPHOX were observed, with a general down-regulation pattern under the conditions tested (Figure 8). Small changes in gene expression were also reported for FYVE genes from $O$. sativa under abiotic stress even at earlier time points (15 min, $30 \mathrm{~min}, 1 \mathrm{~h}$ ), in addition for genes encoding AtPPI-modifying enzymes under different stresses (Heilmann 2016, Xiao and Shaw 2016). Although our data demands an expression analysis at earlier time points (data analyzed here $30 \mathrm{~min}$ and $4 \mathrm{~h}$ ) to detect rapid and transient changes in transcription, it is plausible that these proteins are mainly controlled at a posttranslational level. In addition, the down-regulation of FYVE and PHOX genes under abiotic stress conditions in contrast with the pattern observed under development also suggest a mechanism of stress-response activation which generally comes at the expense of plant growth or growth-defense tradeoff (Bechtold and Field 2018). Analysis of PpFYVE and PpPHOX promoters revealed several elements associated with stress responses to low temperature and drought, defense and hormones such as salicylic acid, methyl jasmonate and abscisic acid which participate in stress responses (Supplemental Table 5). The $P$. patens genome encodes all components of the core ABA signaling pathway identified in angiosperms, and interestingly several PpFYVE and PpPHOX genes which contains $A B R E, D R E$ and MBS elements in their promoters are upregulated in the anr mutant, which fails to respond to $A B A$ in comparison to the WT when treated with $A B A$ or dehydration (Figure 6, (Stevenson et al. 2016)). Particularly in the WT, PpFAB1, PpFYVE5, PpPRAF2 and $P p A L F Y 1-4$ were the genes with a down-regulation pattern under cold, drought and salt. Down-regulation of MtMZR1 (PRAF) was also observed by drought and salt treatments (Hopkins et al. 2014). In similar trend, all PpPHOX were down-regulated under the conditions evaluated and up-regulated in the anr mutant, with exception of $P p S N X 4 c$ which was upregulated by ABA, salt, cold and dehydration treatments. Therefore, PpSNX4C is a robust candidate in regulating abiotic stress in $P$. patens.

\section{Final conclusions}

We have identified 13 and 9 genes coding for FYVE and PHOX proteins, respectively in $P$. patens. PpFYVE proteins resulted in 6 subfamilies previously described (Class I-VI) and we reported an additional group (Class VII) whose FYVE domain was lost during evolution to higher plants, whereas PpPHOX proteins are classified into 5 subfamilies (Class I-IV) previously described in $A$. thaliana with the exception of class $V$ (PLDs). Several FYVE and $P H O X$ genes have been characterized in $A$. thaliana, but there are still classes whose function is unknown as FYVE proteins from Classes III, V, VI, VII, and PHOX proteins from Classes III and IV. Based on our study, candidate genes were identified in $P$. patens for further functional characterization such as PpPRAF2, PpALFY3, PpFYVE4 during the development of tip growing cells and buds, and $P p S N X 4 c$ under abiotic stress where exciting roles may arise. Proteins as FABs, FYVE1 (FREE1), EREX and SNXs are involved in the endocytic pathway; but recently the role of these proteins such as FYVE2 and FYVE1 at the intersection between the conventional endocytic-based membrane trafficking system to the 
bioRxiv preprint doi: https://doi.org/10.1101/765594; this version posted September 11, 2019. The copyright holder for this preprint (which was not certified by peer review) is the author/funder, who has granted bioRxiv a license to display the preprint in perpetuity. It is made available under aCC-BY-NC-ND 4.0 International license.

vacuole and autophagy in regulating vacuolar degradation have started to emerge and suggest further studies. Finally, our work reinforces the notion that expanding in the use of other organisms such as, Bryophytes will provide progress in our understanding on fundamental aspects of plant development and evolutionary function of phosphoinositide signaling in plants. 


\section{LITERATURE CITED}

Aoyama, T., Y. Hiwatashi, M. Shigyo, R. Kofuji, M. Kubo, M. Ito, and M. Hasebe. 2012. "AP2type transcription factors determine stem cell identity in the moss Physcomitrella patens." Development 139 (17):3120-9. doi: 10.1242/dev.076091.

Bader, G. D., and C. W. Hogue. 2003. "An automated method for finding molecular complexes in large protein interaction networks." BMC Bioinformatics 4:2.

Bak, G., E. J. Lee, Y. Lee, M. Kato, S. Segami, H. Sze, M. Maeshima, and J. U. Hwang. 2013. "Rapid structural changes and acidification of guard cell vacuoles during stomatal closure require phosphatidylinositol 3,5-bisphosphate." Plant Cell 25 (6):2202-16. doi: $10.1105 /$ tpc.113.110411.

Banerjee, S., S. Basu, and S. Sarkar. 2010. "Comparative genomics reveals selective distribution and domain organization of FYVE and PX domain proteins across eukaryotic lineages." BMC Genomics 11:83. doi: 10.1186/1471-2164-11-83.

Barberon, M., G. Dubeaux, C. Kolb, E. Isono, E. Zelazny, and G. Vert. 2014. "Polarization of IRON-REGULATED TRANSPORTER 1 (IRT1) to the plant-soil interface plays crucial role in metal homeostasis." Proc Natl Acad Sci U S A 111 (22):8293-8. doi: 10.1073/pnas.1402262111.

Bechtold, U., and B. Field. 2018. "Molecular mechanisms controlling plant growth during abiotic stress." J Exp Bot 69 (11):2753-2758. doi: 10.1093/jxb/ery157.

Belda-Palazon, B., L. Rodriguez, M. A. Fernandez, M. C. Castillo, E. A. Anderson, C. Gao, M. González-Guzmán, M. Peirats-Llobet, Q. Zhao, N. De Winne, K. Gevaert, G. De Jaeger, L. Jiang, J. Leon, R. T. Mullen, and P. L. Rodriguez. 2016. "FYVE1/FREE1 Interacts with the PYL4 ABA Receptor and Mediates its Delivery to the Vacuolar Degradation Pathway." Plant Cell. doi: 10.1105/tpc.16.00178.

Beuchat, J., E. Scacchi, D. Tarkowska, L. Ragni, M. Strnad, and C. S. Hardtke. 2010. "BRX promotes Arabidopsis shoot growth." New Phytol 188 (1):23-9. doi: 10.1111/j.14698137.2010.03387.x.

Bezanilla, M., A. Pan, and R. S. Quatrano. 2003. "RNA interference in the moss Physcomitrella patens." Plant Physiol 133 (2):470-4. doi: 10.1104/pp.103.024901.

Bolger, A. M., M. Lohse, and B. Usadel. 2014. "Trimmomatic: a flexible trimmer for Illumina sequence data." Bioinformatics 30 (15):2114-20. doi: 10.1093/bioinformatics/btu170.

Bravo, J., D. Karathanassis, C. M. Pacold, M. E. Pacold, C. D. Ellson, K. E. Anderson, P. J. Butler, I. Lavenir, O. Perisic, P. T. Hawkins, L. Stephens, and R. L. Williams. 2001. "The crystal structure of the PX domain from p40(phox) bound to phosphatidylinositol 3-phosphate." Mol Cell 8 (4):829-39.

Bray, N. L., H. Pimentel, P. Melsted, and L. Pachter. 2016. "Near-optimal probabilistic RNAseq quantification." Nat Biotechnol 34 (5):525-7. doi: 10.1038/nbt.3519.

Briggs, G. C., C. F. Mouchel, and C. S. Hardtke. 2006. "Characterization of the plant-specific BREVIS RADIX gene family reveals limited genetic redundancy despite high sequence conservation." Plant Physiol 140 (4):1306-16. doi: 10.1104/pp.105.075382.

Brumbarova, T., and R. Ivanov. 2016. "Differential Gene Expression and Protein Phosphorylation as Factors Regulating the State of the Arabidopsis SNX1 Protein Complexes in Response to Environmental Stimuli." Front Plant Sci 7:1456. doi: 10.3389/fpls.2016.01456.

Buckley, Catherine M., Victoria L. Heath, Aurélie Guého, Cristina Bosmani, Paulina Knobloch, Phumzile Sikakana, Nicolas Personnic, Stephen K. Dove, Robert H. Michell, Roger Meier, Hubert Hilbi, Thierry Soldati, Robert H. Insall, and Jason S. King. 2019. "PIKfyve/Fab1 is required for efficient V-ATPase and hydrolase delivery to phagosomes, phagosomal killing, and restriction of Legionella infection." PLOS Pathogens 15 (2): e1007551. doi: 10.1371/journal.ppat.1007551.

Capella, Matías, Pamela A. Ribone, and Raquel L. Chan. 2015. "Functional characterization of the homeodomain leucine zipper I transcription factor AtHB13 reveals a crucial role in Arabidopsis development." Journal of Experimental Botany 66 (19):5929-5943. doi: $10.1093 / \mathrm{jxb} / \mathrm{erv} 302$.

Chandra, M., Y. K. Chin, C. Mas, J. R. Feathers, B. Paul, S. Datta, K. E. Chen, X. Jia, Z. Yang, S. J. Norwood, B. Mohanty, A. Bugarcic, R. D. Teasdale, W. M. Henne, M. Mobli, and B. M. Collins. 2019. "Classification of the human phox homology (PX) 
domains based on their phosphoinositide binding specificities." Nat Commun 10 (1):1528. doi: 10.1038/s41467-019-09355-y.

Collonnier, C., A. Epert, K. Mara, F. Maclot, A. Guyon-Debast, F. Charlot, C. White, D. G. Schaefer, and F. Nogué. 2016. "CRISPR-Cas9 mediated efficient directed mutagenesis and RAD51-dependent and -independent gene targeting in the moss Physcomitrella patens." Plant Biotechnol J. doi: 10.1111/pbi.12596.

Cove, D., M. Bezanilla, P. Harries, and R. Quatrano. 2006. "Mosses as model systems for the study of metabolism and development." Annu Rev Plant Biol 57:497-520. doi: 10.1146/annurev.arplant.57.032905.105338.

Estrada-Navarrete, G., N. Cruz-Mireles, R. Lascano, X. Alvarado-Affantranger, A. Hernàndez, A. Barraza, J. E. Olivares, M. K. Arthikala, L. Cardenas, C. Quinto, and F. Sanchez. 2016. "An autophagy-related kinase is essential for the symbiotic relationship between Phaseolus vulgaris and both rhizobia and arbuscular mycorrhizal fungi." Plant Cell. doi: 10.1105/tpc.15.01012.

Filimonenko, M., P. Isakson, K. D. Finley, M. Anderson, H. Jeong, T. J. Melia, B. J. Bartlett, K. M. Myers, H. C. Birkeland, T. Lamark, D. Krainc, A. Brech, H. Stenmark, A. Simonsen, and A. Yamamoto. 2010. "The selective macroautophagic degradation of aggregated proteins requires the PI3P-binding protein Alfy." Mol Cell 38 (2):265-79. doi: 10.1016/j.molcel.2010.04.007.

Franssen, H. J., T. T. Xiao, O. Kulikova, X. Wan, T. Bisseling, B. Scheres, and R. Heidstra. 2015. "Root developmental programs shape the Medicago truncatula nodule meristem." Development 142 (17):2941-50. doi: 10.1242/dev.120774.

Gao, C., M. Luo, Q. Zhao, R. Yang, Y. Cui, Y. Zeng, J. Xia, and L. Jiang. 2014. "A unique plant ESCRT component, FREE1, regulates multivesicular body protein sorting and plant growth." Curr Biol 24 (21):2556-63. doi: 10.1016/j.cub.2014.09.014.

Gao, C., X. Zhuang, Y. Cui, X. Fu, Y. He, Q. Zhao, Y. Zeng, J. Shen, M. Luo, and L. Jiang. 2015. "Dual roles of an Arabidopsis ESCRT component FREE1 in regulating vacuolar protein transport and autophagic degradation." Proc Natl Acad Sci U S A 112 (6):1886-91. doi: 10.1073/pnas.1421271112.

Gaullier, J. M., E. Ronning, D. J. Gillooly, and H. Stenmark. 2000. "Interaction of the EEA1 FYVE finger with phosphatidylinositol 3-phosphate and early endosomes. Role of conserved residues." J Biol Chem 275 (32):24595-600. doi: 10.1074/jbc.M906554199.

Gel, B., and E. Serra. 2017. "karyoploteR: an R/Bioconductor package to plot customizable genomes displaying arbitrary data." Bioinformatics 33 (19):3088-3090. doi: 10.1093/bioinformatics/btx346.

Gerth, K., F. Lin, W. Menzel, P. Krishnamoorthy, I. Stenzel, M. Heilmann, and I. Heilmann. 2017. "Guilt by Association: A Phenotype-Based View of the Plant Phosphoinositide Network." Annu Rev Plant Biol 68:349-374. doi: 10.1146/annurev-arplant-042916041022.

Hadjebi, O., E. Casas-Terradellas, F. R. Garcia-Gonzalo, and J. L. Rosa. 2008. "The RCC1 superfamily: from genes, to function, to disease." Biochim Biophys Acta 1783 (8):1467-79. doi: 10.1016/j.bbamcr.2008.03.015.

Hanzawa, T., K. Shibasaki, T. Numata, Y. Kawamura, T. Gaude, and A. Rahman. 2013. "Cellular auxin homeostasis under high temperature is regulated through a sorting NEXIN1-dependent endosomal trafficking pathway." Plant Cell 25 (9):3424-33. doi: 10.1105/tpc.113.115881.

Heilmann, I. 2016. "Plant phosphoinositide signaling - dynamics on demand." Biochim Biophys Acta. doi: 10.1016/j.bbalip.2016.02.013.

Heucken, N., and R. Ivanov. 2018. "The retromer, sorting nexins and the plant endomembrane protein trafficking." J Cell Sci 131 (2). doi: 10.1242/jcs.203695.

Hirano, T., T. Matsuzawa, K. Takegawa, and M. H. Sato. 2011. "Loss-of-function and gain-offunction mutations in FAB1A/B impair endomembrane homeostasis, conferring pleiotropic developmental abnormalities in Arabidopsis." Plant Physiol 155 (2):797807. doi: 10.1104/pp.110.167981.

Hirano, T., T. Munnik, and M. H. Sato. 2015. "Phosphatidylinositol 3-Phosphate 5-Kinase, FAB1/PIKfyve Kinase Mediates Endosome Maturation to Establish EndosomeCortical Microtubule Interaction in Arabidopsis." Plant Physiol 169 (3):1961-74. doi: 10.1104/pp.15.01368. 
Hirano, T., T. Munnik, and M. H. Sato. 2017. "Inhibition of phosphatidylinositol 3,5bisphosphate production has pleiotropic effects on various membrane trafficking routes in Arabidopsis." Plant Cell Physiol 58 (1):120-129. doi: 10.1093/pcp/pcw164.

Hopkins, J., O. Pierre, T. Kazmierczak, V. Gruber, F. Frugier, M. Clement, P. Frendo, D. Herouart, and E. Boncompagni. 2014. "MtZR1, a PRAF protein, is involved in the development of roots and symbiotic root nodules in Medicago truncatula." Plant Cell Environ 37 (3):658-69. doi: 10.1111/pce.12185.

Horstman, Anneke, Hiroyuki Fukuoka, Jose M. Muino, Lisette Nitsch, Changhua Guo, Paul Passarinho, Gabino Sanchez-Perez, Richard Immink, Gerco Angenent, and Kim Boutilier. 2015. "AIL and HDG proteins act antagonistically to control cell proliferation." Development 142 (3):454. doi: 10.1242/dev.117168.

Ivanov, R., T. Brumbarova, A. Blum, A. M. Jantke, C. Fink-Straube, and P. Bauer. 2014. "SORTING NEXIN1 is required for modulating the trafficking and stability of the Arabidopsis IRON-REGULATED TRANSPORTER1." Plant Cell 26 (3):1294-307. doi: 10.1105/tpc.113.116244.

Jaillais, Y., I. Fobis-Loisy, C. Miège, and T. Gaude. 2008. "Evidence for a sorting endosome in Arabidopsis root cells." Plant J 53 (2):237-47. doi: 10.1111/j.1365313X.2007.03338.X.

Jaillais, Y., I. Fobis-Loisy, C. Miège, C. Rollin, and T. Gaude. 2006. "AtSNX1 defines an endosome for auxin-carrier trafficking in Arabidopsis." Nature 443 (7107):106-9. doi: 10.1038/nature05046.

Jensen, R. B., T. La Cour, J. Albrethsen, M. Nielsen, and K. Skriver. 2001. "FYVE zinc-finger proteins in the plant model Arabidopsis thaliana: identification of Ptdlns3P-binding residues by comparison of classic and variant FYVE domains." Biochem J 359 (Pt 1):165-73.

Joo, J. H., H. J. Yoo, I. Hwang, J. S. Lee, K. H. Nam, and Y. S. Bae. 2005. "Auxin-induced reactive oxygen species production requires the activation of phosphatidylinositol 3kinase." FEBS Lett 579 (5):1243-8. doi: 10.1016/j.febslet.2005.01.018.

Kale, S. D., B. Gu, D. G. Capelluto, D. Dou, E. Feldman, A. Rumore, F. D. Arredondo, R. Hanlon, I. Fudal, T. Rouxel, C. B. Lawrence, W. Shan, and B. M. Tyler. 2010. "External lipid PI3P mediates entry of eukaryotic pathogen effectors into plant and animal host cells." Cell 142 (2):284-95. doi: 10.1016/j.cell.2010.06.008.

Kolb, C., M. K. Nagel, K. Kalinowska, J. Hagmann, M. Ichikawa, F. Anzenberger, A. Alkofer, M. H. Sato, P. Braun, and E. Isono. 2015. "FYVE1 is essential for vacuole biogenesis and intracellular trafficking in Arabidopsis." Plant Physiol 167 (4):1361-73. doi: 10.1104/pp.114.253377.

Kutateladze, T. G. 2006. "Phosphatidylinositol 3-phosphate recognition and membrane docking by the FYVE domain." Biochim Biophys Acta 1761 (8):868-77. doi: 10.1016/j.bbalip.2006.03.011.

Lee, Y., G. Bak, Y. Choi, W. I. Chuang, and H. T. Cho. 2008. "Roles of phosphatidylinositol 3kinase in root hair growth." Plant Physiol 147 (2):624-35. doi: 10.1104/pp.108.117341.

Lee, Y., E. S. Kim, Y. Choi, I. Hwang, C. J. Staiger, and Y. Y. Chung. 2008. "The Arabidopsis phosphatidylinositol 3-kinase is important for pollen development." Plant Physiol 147 (4): 1886-97. doi: 10.1104/pp.108.121590.

Leprince, A. S., N. Magalhaes, D. De Vos, M. Bordenave, E. Crilat, G. Clément, C. Meyer, T. Munnik, and A. Savouré. 2014. "Involvement of Phosphatidylinositol 3-kinase in the regulation of proline catabolism in Arabidopsis thaliana." Front Plant Sci 5:772. doi: 10.3389/fpls.2014.00772.

Leshem, Y., L. Seri, and A. Levine. 2007. "Induction of phosphatidylinositol 3-kinasemediated endocytosis by salt stress leads to intracellular production of reactive oxygen species and salt tolerance." Plant J 51 (2):185-97. doi: 10.1111/j.1365313X.2007.03134.X.

Liu, J., J. Zhou, and D. Xing. 2012. "Phosphatidylinositol 3-kinase plays a vital role in regulation of rice seed vigor via altering NADPH oxidase activity." PLoS One 7 (3):e33817. doi: 10.1371/journal.pone.0033817.

Meijer, Harold J. G., Nullin Divecha, Herman van den Ende, Alan Musgrave, and Teun Munnik. 1999. "Hyperosmotic stress induces rapid synthesis of phosphatidyl-Dinositol 3,5-bisphosphate in plant cells." Planta 208 (2):294-298. doi:

$10.1007 / \mathrm{s} 004250050561$. 
Moravcevic, K., C. L. Oxley, and M. A. Lemmon. 2012. "Conditional peripheral membrane proteins: facing up to limited specificity." Structure 20 (1):15-27. doi:

10.1016/j.str.2011.11.012.

Moreno-Risueno, M. A., R. Sozzani, G. G. Yardımcı, J. J. Petricka, T. Vernoux, I. Blilou, J. Alonso, C. M. Winter, U. Ohler, B. Scheres, and P. N. Benfey. 2015. "Transcriptional control of tissue formation throughout root development." Science 350 (6259):42630. doi: 10.1126/science.aad1171.

Mouchel, C. F., G. C. Briggs, and C. S. Hardtke. 2004. "Natural genetic variation in Arabidopsis identifies BREVIS RADIX, a novel regulator of cell proliferation and elongation in the root." Genes Dev 18 (6):700-14. doi: 10.1101/gad.1187704.

Mueller-Roeber, B., and C. Pical. 2002. "Inositol phospholipid metabolism in Arabidopsis. Characterized and putative isoforms of inositol phospholipid kinase and phosphoinositide-specific phospholipase C." Plant Physiol 130 (1):22-46. doi: 10.1104/pp.004770.

Ortiz-Ramírez, C., M. Hernandez-Coronado, A. Thamm, B. Catarino, M. Wang, L. Dolan, J. A. Feijó, and J. D. Becker. 2016. "A Transcriptome Atlas of Physcomitrella patens Provides Insights into the Evolution and Development of Land Plants." Mol Plant 9 (2):205-20. doi: 10.1016/j.molp.2015.12.002.

Park, K. Y., J. Y. Jung, J. Park, J. U. Hwang, Y. W. Kim, I. Hwang, and Y. Lee. 2003. "A role for phosphatidylinositol 3-phosphate in abscisic acid-induced reactive oxygen species generation in guard cells." Plant Physiol 132 (1):92-8. doi: 10.1104/pp.102.016964.

Peleg-Grossman, S., H. Volpin, and A. Levine. 2007. "Root hair curling and Rhizobium infection in Medicago truncatula are mediated by phosphatidylinositide-regulated endocytosis and reactive oxygen species." J Exp Bot 58 (7):1637-49. doi: 10.1093/jxb/erm013.

Phan, N. Q., S. J. Kim, and D. C. Bassham. 2008. "Overexpression of Arabidopsis sorting nexin AtSNX2b inhibits endocytic trafficking to the vacuole." Mol Plant 1 (6):961-76. doi: $10.1093 / \mathrm{mp} / \mathrm{ssn} 057$.

Pourcher, M., M. Santambrogio, N. Thazar, A. M. Thierry, I. Fobis-Loisy, C. Miège, Y. Jaillais, and T. Gaude. 2010. "Analyses of sorting nexins reveal distinct retromer-subcomplex functions in development and protein sorting in Arabidopsis thaliana." Plant Cell 22 (12):3980-91. doi: 10.1105/tpc.110.078451.

Rensing, S. A. 2017. "Why we need more non-seed plant models." New Phytol 216 (2):355360. doi: $10.1111 / \mathrm{nph} .14464$.

Rensing, S. A., D. Lang, A. D. Zimmer, A. Terry, A. Salamov, H. Shapiro, T. Nishiyama, P. F. Perroud, E. A. Lindquist, Y. Kamisugi, T. Tanahashi, K. Sakakibara, T. Fujita, K. Oishi, T. Shin-I, Y. Kuroki, A. Toyoda, Y. Suzuki, S. Hashimoto, K. Yamaguchi, S. Sugano, Y. Kohara, A. Fujiyama, A. Anterola, S. Aoki, N. Ashton, W. B. Barbazuk, E. Barker, J. L. Bennetzen, R. Blankenship, S. H. Cho, S. K. Dutcher, M. Estelle, J. A. Fawcett, H. Gundlach, K. Hanada, A. Heyl, K. A. Hicks, J. Hughes, M. Lohr, K. Mayer, A. Melkozernov, T. Murata, D. R. Nelson, B. Pils, M. Prigge, B. Reiss, T. Renner, S. Rombauts, P. J. Rushton, A. Sanderfoot, G. Schween, S. H. Shiu, K. Stueber, F. L. Theodoulou, H. Tu, Y. Van de Peer, P. J. Verrier, E. Waters, A. Wood, L. Yang, D. Cove, A. C. Cuming, M. Hasebe, S. Lucas, B. D. Mishler, R. Reski, I. V. Grigoriev, R. S. Quatrano, and J. L. Boore. 2008. "The Physcomitrella genome reveals evolutionary insights into the conquest of land by plants." Science 319 (5859):64-9. doi: 10.1126/science.1150646.

Ritchie, M. E., B. Phipson, D. Wu, Y. Hu, C. W. Law, W. Shi, and G. K. Smyth. 2015. "limma powers differential expression analyses for RNA-sequencing and microarray studies." Nucleic Acids Res 43 (7):e47. doi: 10.1093/nar/gkv007.

Robert, G., N. Muñoz, X. Alvarado-Affantranger, L. Saavedra, V. Davidenco, M. RodríguezKessler, G. Estrada-Navarrete, F. Sánchez, and R. Lascano. 2018. "Phosphatidylinositol 3-kinase at The Very Early Symbiont Perception: A Local Nodulation Control under Stress Conditions?" J Exp Bot. doi: 10.1093/jxb/ery030.

Robinson, M. D., D. J. McCarthy, and G. K. Smyth. 2010. "edgeR: a Bioconductor package for differential expression analysis of digital gene expression data." Bioinformatics 26 (1):139-40. doi: 10.1093/bioinformatics/btp616.

Saavedra, L., V. Balbi, S. K. Dove, Y. Hiwatashi, K. Mikami, and M. Sommarin. 2009. "Characterization of phosphatidylinositol phosphate kinases from the moss 
Physcomitrella patens: PpPIPK1 and PpPIPK2." Plant Cell Physiol 50 (3):595-609. doi: $10.1093 / p c p / p c p 018$.

Saavedra, L., R. Catarino, T. Heinz, I. Heilmann, M. Bezanilla, and R. Malhó. 2015. "Phosphatase and Tensin Homolog Is a Growth Repressor of Both Rhizoid and Gametophore Development in the Moss Physcomitrella patens." Plant Physiol 169 (4):2572-86. doi: 10.1104/pp.15.01197.

Saddic, Louis A., Bärbel Huvermann, Staver Bezhani, Yanhui Su, Cara M. Winter, Chang Seob Kwon, Richard P. Collum, and Doris Wagner. 2006. "The LEAFY target LMI1 is a meristem identity regulator and acts together with LEAFY to regulate expression of <em>CAULIFLOWER</em>." Development 133 (9):1673. doi: 10.1242/dev.02331.

Sakurai, H. T., T. Inoue, A. Nakano, and T. Ueda. 2016. "ENDOSOMAL RAB EFFECTOR WITH PX-DOMAIN, an Interacting Partner of RAB5 GTPases, Regulates Membrane Trafficking to Protein Storage Vacuoles in Arabidopsis." Plant Cell 28 (6):1490-503. doi: $10.1105 /$ tpc. 16.00326.

Schaefer, D. G., and J. P. Zrÿd. 1997. "Efficient gene targeting in the moss Physcomitrella patens." Plant J 11 (6):1195-206.

Schink, K. O., C. Raiborg, and H. Stenmark. 2013. "Phosphatidylinositol 3-phosphate, a lipid that regulates membrane dynamics, protein sorting and cell signalling." Bioessays 35 (10):900-12. doi: 10.1002/bies.201300064.

Schink, K. O., K. W. Tan, and H. Stenmark. 2016. "Phosphoinositides in Control of Membrane Dynamics." Annu Rev Cell Dev Biol 32:143-171. doi: 10.1146/annurev-cellbio111315-125349.

Seet, L. F., and W. Hong. 2006. "The Phox (PX) domain proteins and membrane traffic." Biochim Biophys Acta 1761 (8):878-96. doi: 10.1016/j.bbalip.2006.04.011.

Serrazina, S., F. V. Dias, and R. Malhó. 2014. "Characterization of FAB1 phosphatidylinositol kinases in Arabidopsis pollen tube growth and fertilization." New Phytol 203 (3):78493. doi: 10.1111/nph.12836.

Shannon, P., A. Markiel, O. Ozier, N. S. Baliga, J. T. Wang, D. Ramage, N. Amin, B. Schwikowski, and T. Ideker. 2003. "Cytoscape: a software environment for integrated models of biomolecular interaction networks." Genome Res 13 (11):2498-504. doi: 10.1101/gr.1239303.

Simonsen, A., H. C. Birkeland, D. J. Gillooly, N. Mizushima, A. Kuma, T. Yoshimori, T. Slagsvold, A. Brech, and H. Stenmark. 2004. "Alfy, a novel FYVE-domain-containing protein associated with protein granules and autophagic membranes." J Cell Sci 117 (Pt 18):4239-51. doi: 10.1242/jcs.01287.

Son, O., H. Y. Cho, M. R. Kim, H. Lee, M. S. Lee, E. Song, J. H. Park, K. H. Nam, J. Y. Chun, H. J. Kim, S. K. Hong, Y. Y. Chung, C. G. Hur, H. T. Cho, and C. I. Cheon. 2005. "Induction of a homeodomain-leucine zipper gene by auxin is inhibited by cytokinin in Arabidopsis roots." Biochem Biophys Res Commun 326 (1):203-9. doi: 10.1016/j.bbrc.2004.11.014.

Stevenson, S. R., Y. Kamisugi, C. H. Trinh, J. Schmutz, J. W. Jenkins, J. Grimwood, W. Muchero, G. A. Tuskan, S. A. Rensing, D. Lang, R. Reski, M. Melkonian, C. J. Rothfels, F. W. Li, A. Larsson, G. K. Wong, T. A. Edwards, and A. C. Cuming. 2016. "Genetic Analysis of Physcomitrella patens Identifies ABSCISIC ACID NONRESPONSIVE, a Regulator of ABA Responses Unique to Basal Land Plants and Required for Desiccation Tolerance." Plant Cell 28 (6):1310-27. doi: 10.1105/tpc.16.00091.

Sutipatanasomboon, A., S. Herberth, E. G. Alwood, H. Häweker, B. Müller, M. Shahriari, A. Y. Zienert, B. Marin, S. Robatzek, G. J. K. Praefcke, K. R. Ayscough, M. Hülskamp, and S. Schellmann. 2017. "Disruption of the plant-specific CFS1 gene impairs autophagosome turnover and triggers EDS1-dependent cell death." Sci Rep 7 (1):8677. doi: 10.1038/s41598-017-08577-8.

Thelander, M., K. Landberg, and E. Sundberg. 2018. "Auxin-mediated developmental control in the moss Physcomitrella patens." J Exp Bot 69 (2):277-290. doi: 10.1093/jxb/erx255.

van Gisbergen, P. A., M. Li, S. Z. Wu, and M. Bezanilla. 2012. "Class II formin targeting to the cell cortex by binding $\mathrm{PI}(3,5) \mathrm{P}(2)$ is essential for polarized growth." J Cell Biol 198 (2):235-50. doi: 10.1083/jcb.201112085.

van Leeuwen, W., L. Okrész, L. Bögre, and T. Munnik. 2004. "Learning the lipid language of plant signalling." Trends Plant Sci 9 (8):378-84. doi: 10.1016/j.tplants.2004.06.008. 
bioRxiv preprint doi: https://doi.org/10.1101/765594; this version posted September 11, 2019. The copyright holder for this preprint (which was not certified by peer review) is the author/funder, who has granted bioRxiv a license to display the preprint in perpetuity. It is made available under aCC-BY-NC-ND 4.0 International license.

Vidali, L., and M. Bezanilla. 2012. "Physcomitrella patens: a model for tip cell growth and differentiation." Curr Opin Plant Biol 15 (6):625-31. doi: 10.1016/j.pbi.2012.09.008.

Whitley, P., S. Hinz, and J. Doughty. 2009. "Arabidopsis FAB1/PIKfyve proteins are essential for development of viable pollen." Plant Physiol 151 (4):1812-22. doi: 10.1104/pp.109.146159.

Wywial, E., and S. M. Singh. 2010. "Identification and structural characterization of FYVE domain-containing proteins of Arabidopsis thaliana." BMC Plant Biol 10:157. doi: 10.1186/1471-2229-10-157.

Xiao, L., H. Wang, P. Wan, T. Kuang, and Y. He. 2011. "Genome-wide transcriptome analysis of gametophyte development in Physcomitrella patens." BMC Plant Biol 11:177. doi: 10.1186/1471-2229-11-177.

Xiao, L., L. Zhang, G. Yang, H. Zhu, and Y. He. 2012. "Transcriptome of protoplasts reprogrammed into stem cells in Physcomitrella patens." PLoS One 7 (4):e35961. doi: 10.1371/journal.pone.0035961.

Xiao, Shanshan, and Min Dong Wang Li Shaw, Wenqi Liu, Fengquan. 2016. Identification and Evolution of FYVE Domain-Containing Proteins and Their Expression Patterns in Response to Abiotic Stresses in Rice. Plant Molecular Biology Reporter.

Zhuang, X., and L. Jiang. 2014. "Autophagosome biogenesis in plants: roles of SH3P2." Autophagy 10 (4):704-5. doi: 10.4161/auto.28060. 


\section{FIGURE LEGENDS}

Figure 1. Chromosome localization and nomenclature of the PpPFYVE and PpPHOX genes in P. patens.

Figure 2. The FYVE and PHOX domain protein families in $P$. patens. Schematic diagram of the domain structures of the known plant FYVE and PHOX domain containing plant proteins. The nomenclature for the different proteins is shown in the right.

Figure 3. Phylogenetic analysis of FYVE proteins (classes I-VII) from Chlorophytes (Chlamydomonas reinhardtii and Volvox carterii), Charophytes (Klebsormidium nitens), Bryophytes (Physcomitrella patens, Sphagnum fallax, Marchantia polymorpha), Lycophytes (Selaginella moellendorffii) and Angiosperms (Arabidopsis thaliana, Glycine Max, Vitis vinifera and Oryza sativa).

Figure 4. Phylogenetic analysis of PHOX proteins (classes I-IV) from Chlorophytes (Chlamydomonas reinhardtii and Volvox carterii), Charophytes (Klebsormidium nitens), Bryophytes (Physcomitrella patens, Sphagnum fallax, Marchantia polymorpha), Lycophytes (Selaginella moellendorffii) and Angiosperms (Arabidopsis thaliana, Glycine Max, Vitis vinifera and Oryza sativa).

Figure 5. Gene-motif interaction network of PpFYVE genes. Motifs were filtered by a motifScore $>10$ and a degree $>4$. Nodes are represented as PpFYVE transcripts (in pink) and motifs (in blue), edges show their interaction (gray dash line).

Figure 6. Gene-motif interaction network of $P p P H O X$ genes. Motifs were filtered by a motifScore $>10$ and a degree $>4$. Nodes are represented as PpPHOX transcripts (in purple) and motifs (in light blue), edges show their interaction (gray dash line).

Figure 7. Heatmap analysis of the PpFYVE and $P p P H O X$ genes during developmental stages of $P$. patens life cycle. Gene expression of PpFYVE and PpPHOX were assessed in three RNAseq studies (columns) and a hierarchical cluster analysis was applied at transcript level (rows). Studies from left to right: protoplast (PRJNA153001; Xiao, et al 2012), developmental tissues (PRJNA265205; Frank, et al 2015) and developmental stages (DS) (PRJNA149079; Xiao L., et al 2011). Comparisons are denoted by the character [/]. Key color represents the fold change values, up-regulated genes (red) and down-regulated (blue). Abbreviations: pp, protoplast; WP, whole plant; GAC, gametophore apical cell; YS, young sporophyte; DS, developmental stage; Caul, caulonema; Chlo, chloronema.

Figure 8. Heatmap analysis of the PpFYVE and PpPHOX genes under different abiotic stress treatments in $P$. patens. Gene expression of PpFYVE and PpPHOX were assessed in two RNAseq studies (columns) and a hierarchical cluster analysis was applied at transcript level (rows). Studies from left to right: anr mutant (PRJNA294412; Stevenson et al 2016), abiotic treatments through the time (PRJNA266515). Comparisons are denoted by the character [/]. Key color represents the fold change values, up-regulated genes (red) and down-regulated (blue). Abbreviations: anr (aba non-responsive), WT (Wild Type), and ABA (abscisic acid). 


\section{ADDITIONAL INFORMATION}

Supplementary information that accompanies this paper:

Figure S1- Sequence alignment and motif analysis of the FYVE domain of the repertory of FYVE proteins in $P$. patens and $A$. thaliana.

Figure S2- Sequence alignment and motif analysis of the PHOX domain of the repertory of PHOX proteins in $P$. patens and $A$. thaliana.

Figure S3- Summary of statistics of the several RNA sequencing studies assessed here. (A) Mean Quality Scores graphic. Lines in green represent each library with quality score $>20$ Phred Score. (B) Barplot shows the library fragment size before (pink) and after (blue) trimming. (C) Barplot depicts the number of reads by library before (pink) and after (blue) trimming. (D) Stacked barplot summarizes the percentage of mapped (pink) and unmapped (blue) reads by library from the pseudo - bam files obtained by Kallisto (Bray, Pimentel, Melsted, \& Pachter, 2016).

Table S1- FYVE and PHOX genes used in this study.

Table S2- PpFYVE intron-exon structure.

Table S3- $P p P H O X$ intron-exon structure.

Table S4- Pfam scan PLDs.

Table S5- $P p F Y V E$ and $P p P H O X$ promoter cis-acting regulatory elements analyzed with PlantCARE.

Table S6- $P p F Y V E$ and $P p P H O X$ promoter transcription factor binding sites analyzed with PlantPAN2.0.

Table S7- Scoring tables of the known motif analysis (Homer v4.977) of PpFYVE genes.

Table S8- Scoring tables of the known motif analysis (Homer v4.977) of PpPHOX genes.

Table S9- Interaction network analysis of the known motifs of the PpPHOX and PpFYVE genes in Cytoscape (v3.6.1). (a) Motif-gene interaction network file of PpPHOX genes. (b) Node-scoring table of $P p P H O X$ net build by Molecular Complex Detection (MCODE) App. (c) Motif-gene interaction network file of PpFYVE genes. (d) Node-scoring table of PpFYVE net build by MCODE.

Table S8- Bioproject list of the transcriptomic studies in Physcomitrella patens surveyed on the SRA and GEO databases from the NCBI website. 


\section{ACKNOWLEDGEMENTS}

This work was supported by grants from the Agencia Nacional de Promoción Científica y Tecnológica, Argentina (FONCYT-PICT-2016-0497), Consejo Nacional de Investigaciones Científicas y Técnicas (CONICET) and Secretaria de Ciencia y Tecnología (SECYT) Universidad Nacional de Córdoba (UNC). Additional funding was provided by the Portuguese Foundation for Science and Technology (FCT Investigator IF/00169/2015), and UID/MULTI/04046/2019 Research Unit grant from FCT to BiolSI.

\section{AUTHOR CONTRIBUTIONS}

L.S., P.A-R., and M.F. designed the study. P.A.-R., M.F, L.S. and T.S. analyzed the data. L.S., A.F. and P.A.-R. wrote the manuscript with valuable input from R.L. All the authors revised and approved the manuscript. 
bioRxiv preprint doi: https://doi.org/10.1101/765594; this version posted September 11,2019 . The copyright holder for this preprint (which was not certified by peer review) is the author/funder, who has granted bioRxiv a license to display the preprint in perpetuity. It is made available under aCC-BY-NC-ND 4.0 International license.

\section{FIGURES}

\section{Figure 1.}

A.

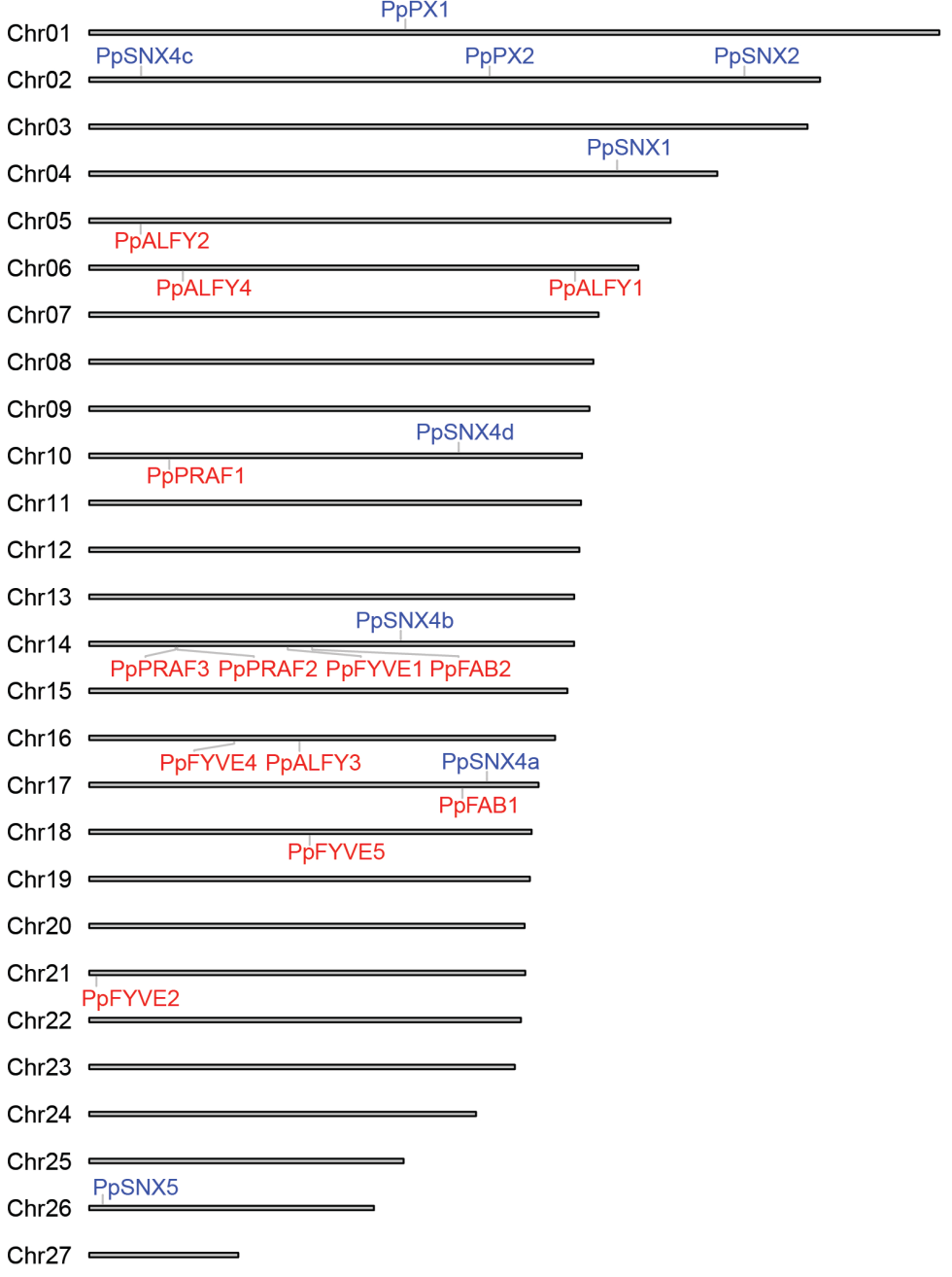

B.

\begin{tabular}{|l|l|}
\hline PpFYVE & \\
\hline PpFAB1 & Pp3c17_19810 \\
\hline PpFAB2 & Pp3c14_12410 \\
\hline PpFYVE2 & Pp3c21_290 \\
\hline PpFYVE4 & Pp3c16_8350 \\
\hline PpFYVE1 & Pp3c14_11260 \\
\hline PpPRAF1 & Pp3c10_3890 \\
\hline PpPRAF2 & Pp3c14_4760 \\
\hline PpPRAF3 & Pp3c14_4640 \\
\hline PpFYVE5 & Pp3c18_11010 \\
\hline PpALFY1 & Pp3c6_26100 \\
\hline PpALFY2 & Pp3c5_2890 \\
\hline PpALFY3 & Pp3c16_11700 \\
\hline PpALFY4 & Pp3c6_5700 \\
\hline PpPHOX & \\
\hline PpSNX1 & Pp3c4_27410 \\
\hline PpSNX2 & Pp3c2_34810 \\
\hline PpSNX4a & Pp3c17_21440 \\
\hline PpSNX4b & Pp3c14_16910 \\
\hline PpSNX4c & Pp3c2_2780 \\
\hline PpSNX4d & Pp3c10_18970 \\
\hline PpSNX5 & Pp3c26_1280 \\
\hline PpPX1 & Pp3c1_14920 \\
\hline PpPX2 & Pp3c2_21590 \\
\hline &
\end{tabular}


bioRxiv preprint doi: https://doi.org/10.1101/765594; this version posted September 11, 2019. The copyright holder for this preprint (which was not certified by peer review) is the author/funder, who has granted bioRxiv a license to display the preprint in perpetuity. It is made available under aCC-BY-NC-ND 4.0 International license.

Figure 2.

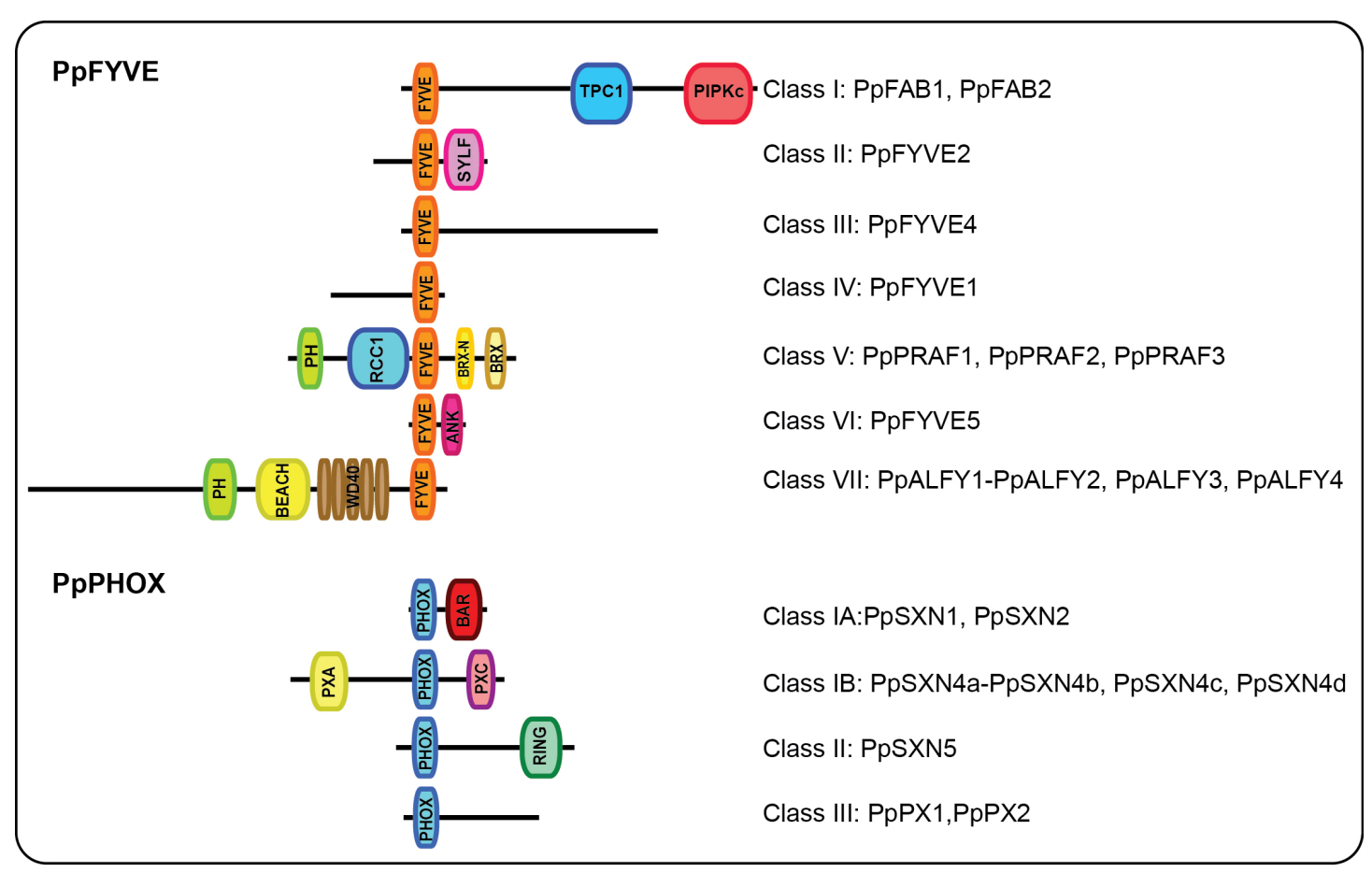


bioRxiv preprint doi: https://doi.org/10.1101/765594; this version posted September 11,2019 . The copyright holder for this preprint (which was not certified by peer review) is the author/funder, who has granted bioRxiv a license to display the preprint in perpetuity. It is made available under aCC-BY-NC-ND 4.0 International license.

\section{Figure 3.}

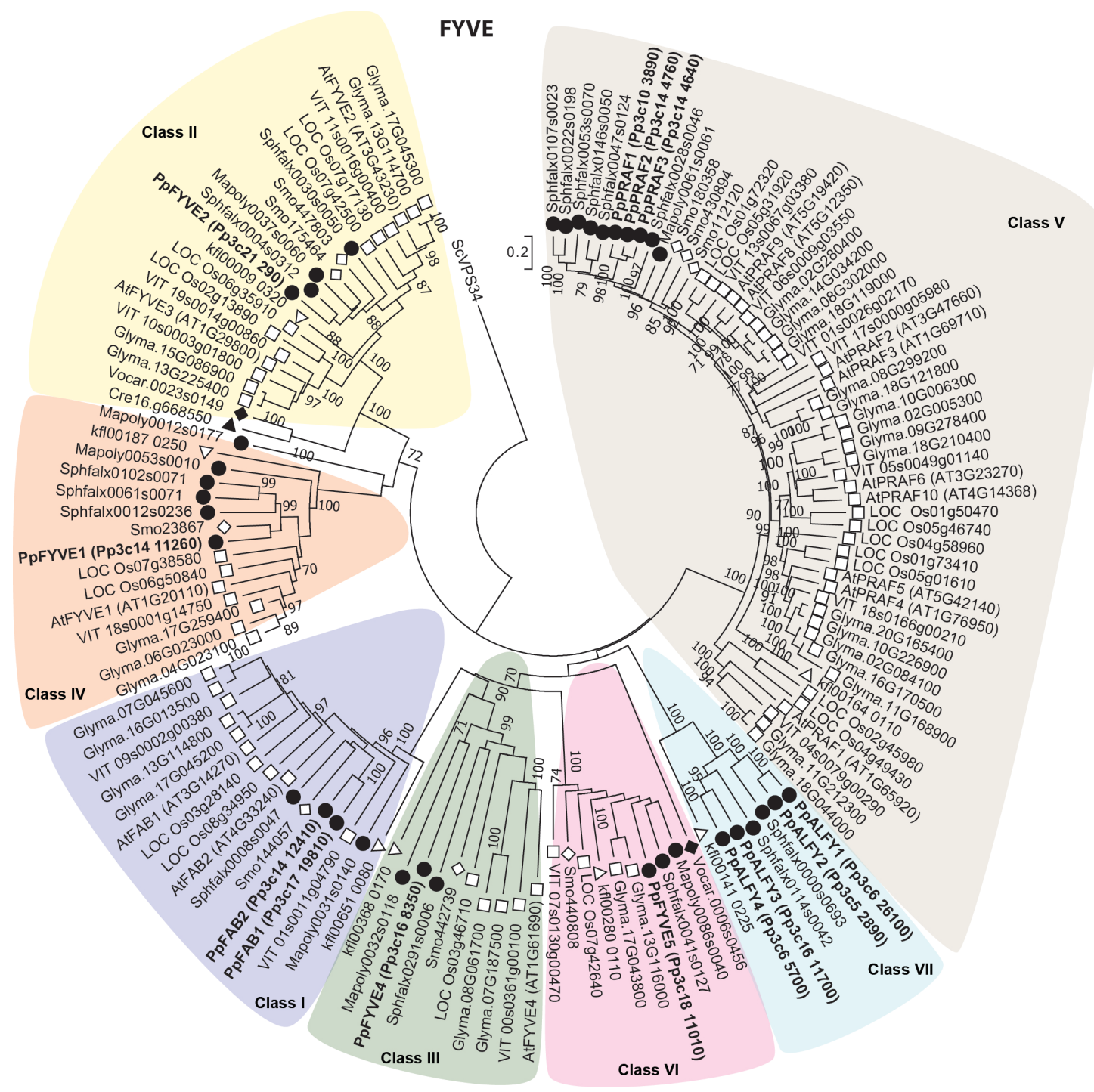


bioRxiv preprint doi: https://doi.org/10.1101/765594; this version posted September 11,2019 . The copyright holder for this preprint (which was not certified by peer review) is the author/funder, who has granted bioRxiv a license to display the preprint in perpetuity. It is made available under aCC-BY-NC-ND 4.0 International license.

\section{Figure 4.}

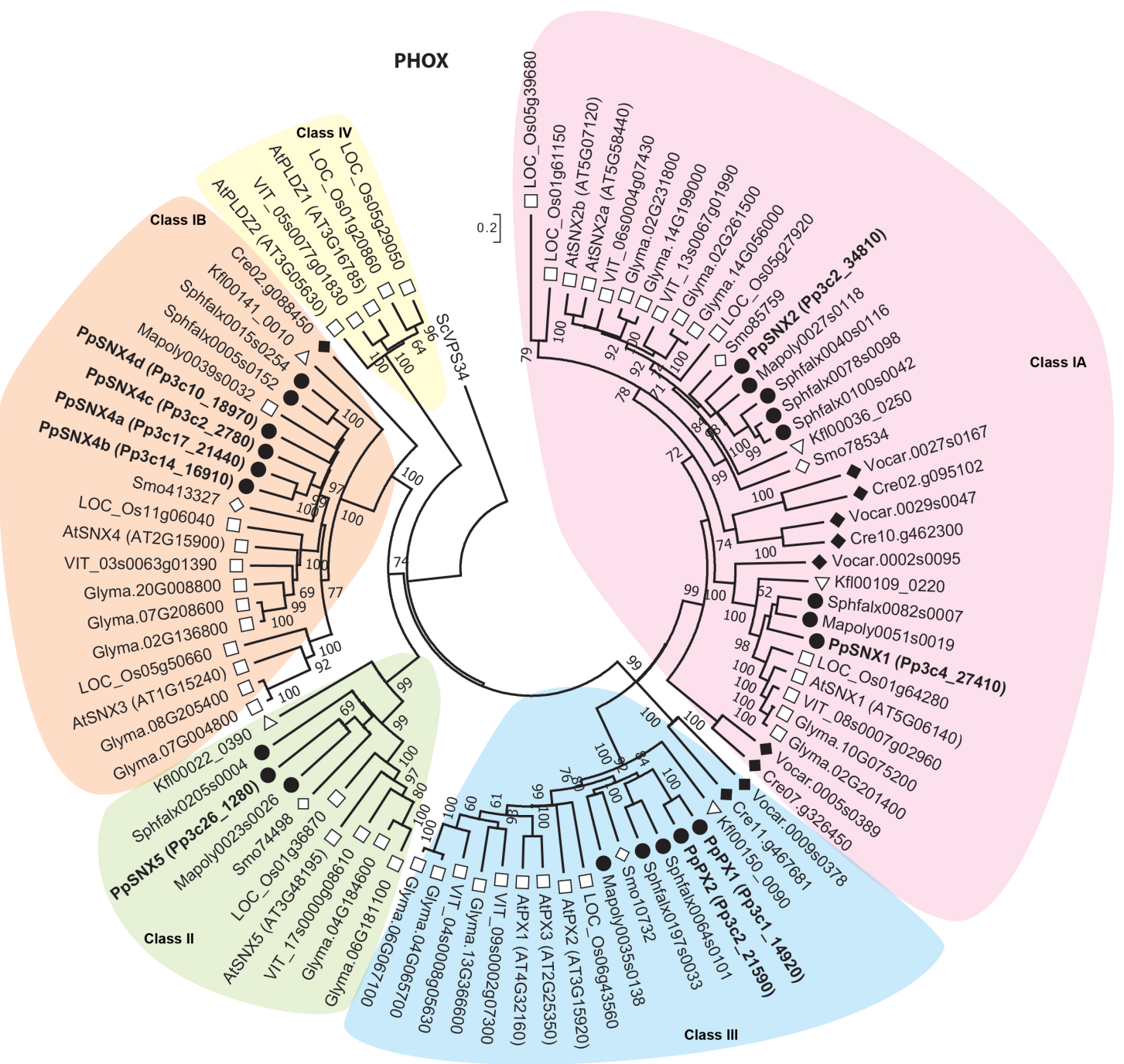


bioRxiv preprint doi: https://doi.org/10.1101/765594; this version posted September 11, 2019. The copyright holder for this preprint (which was not certified by peer review) is the author/funder, who has granted bioRxiv a license to display the preprint in perpetuity. It is made available under aCC-BY-NC-ND 4.0 International license.

\section{Figure 5.}

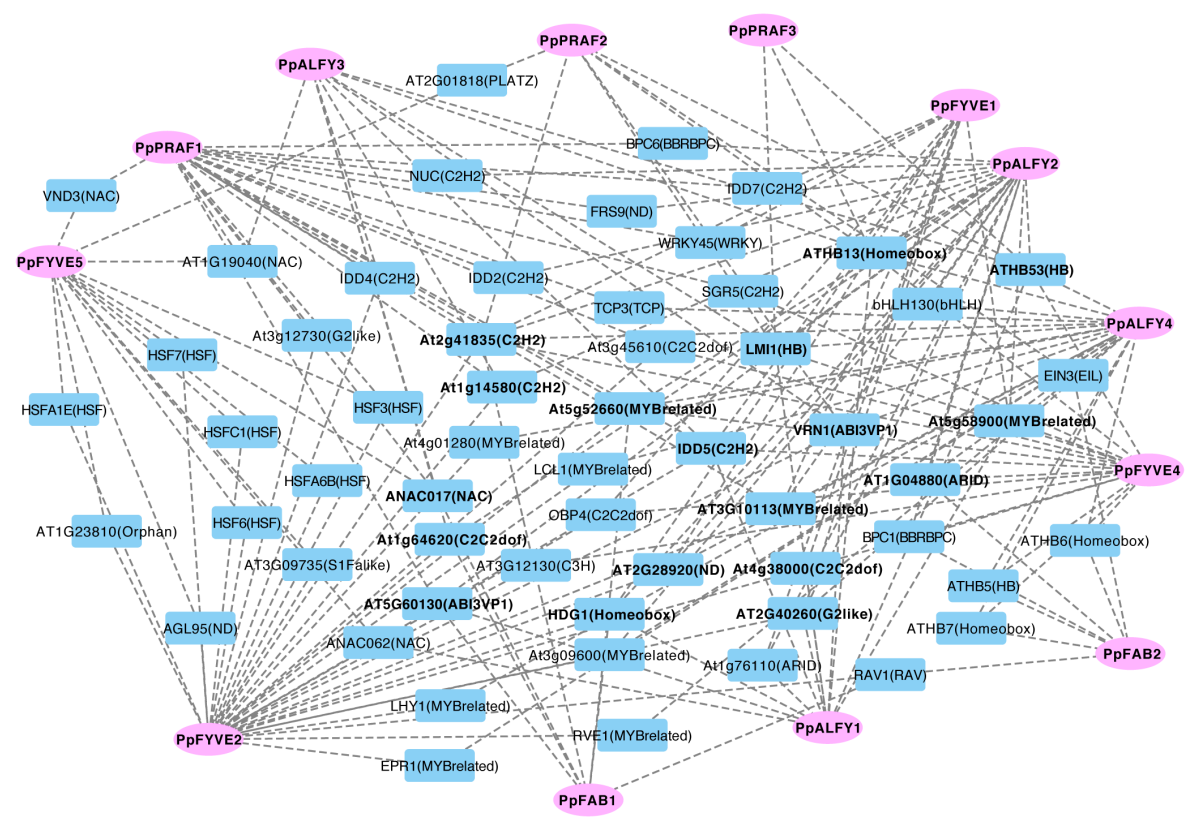


bioRxiv preprint doi: https://doi.org/10.1101/765594; this version posted September 11,2019 . The copyright holder for this preprint (which was not certified by peer review) is the author/funder, who has granted bioRxiv a license to display the preprint in perpetuity. It is made available under aCC-BY-NC-ND 4.0 International license.

\section{Figure 6.}

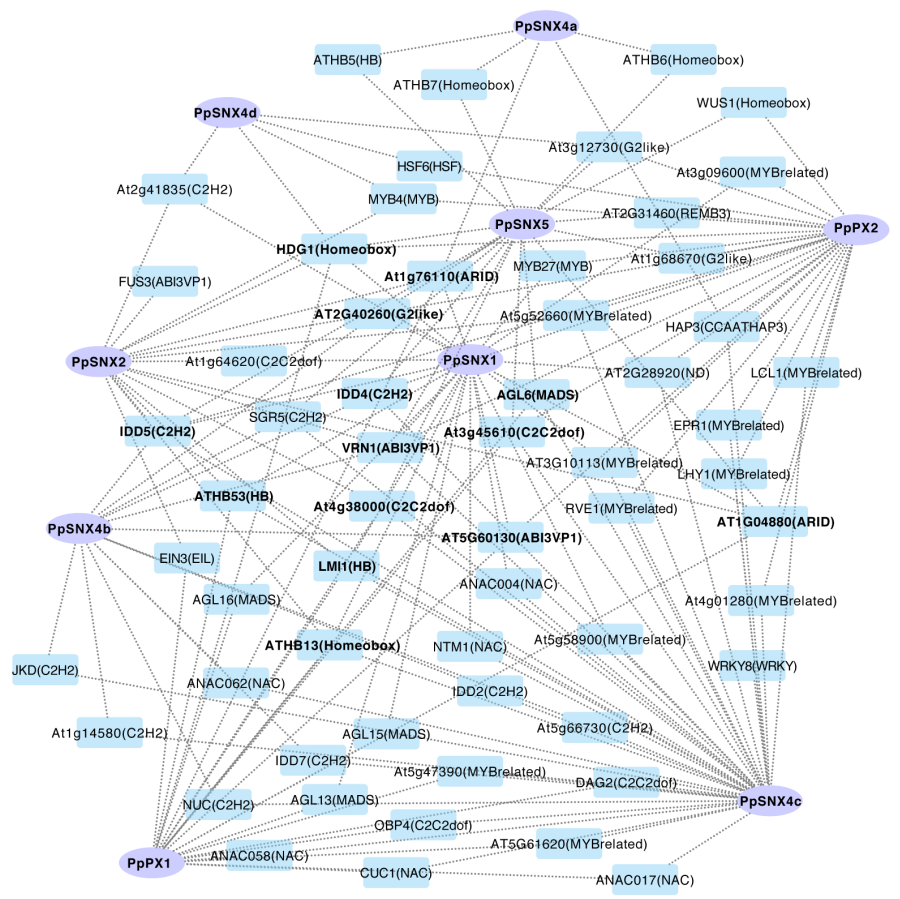


bioRxiv preprint doi: https://doi.org/10.1101/765594; this version posted September 11, 2019. The copyright holder for this preprint (which was not certified by peer review) is the author/funder, who has granted bioRxiv a license to display the preprint in perpetuity. It is made available under aCC-BY-NC-ND 4.0 International license.

Figure 7.

A-
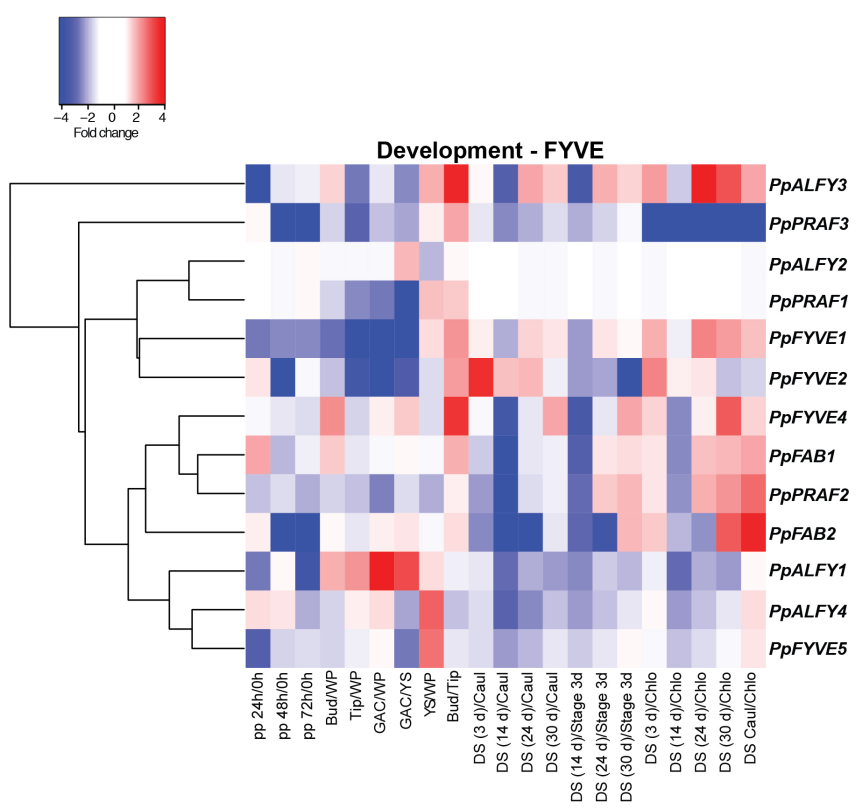

B-
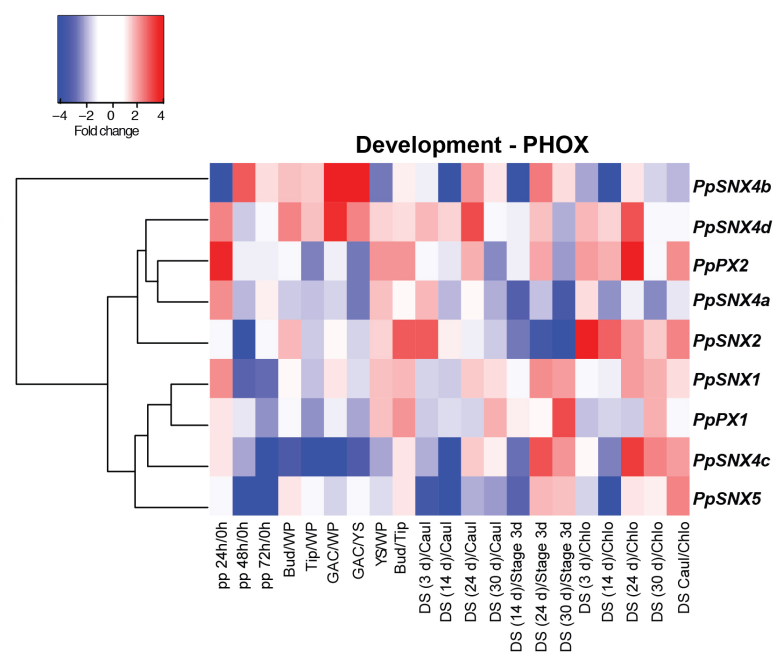
bioRxiv preprint doi: https://doi.org/10.1101/765594; this version posted September 11, 2019. The copyright holder for this preprint (which was not certified by peer review) is the author/funder, who has granted bioRxiv a license to display the preprint in perpetuity. It is made available under aCC-BY-NC-ND 4.0 International license.

Figure 8.

A-
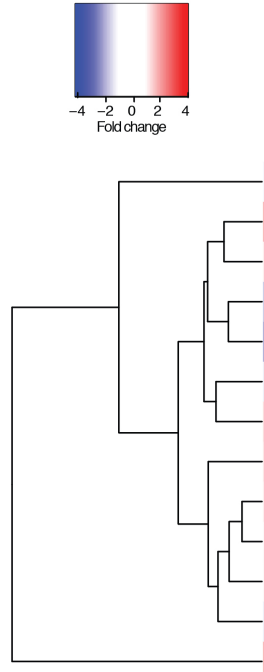

Abiotic Stress- FYVE

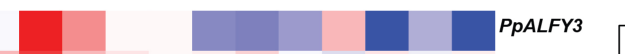

PpPRAF3

PpALFY2

PpPRAF1

PpFYVE1

PpFYVE2

PpFYVE4

PpFAB1

PpPRAF2

PpFAB2

PpALFY1

PPALFY4

PpFYVE5
B-

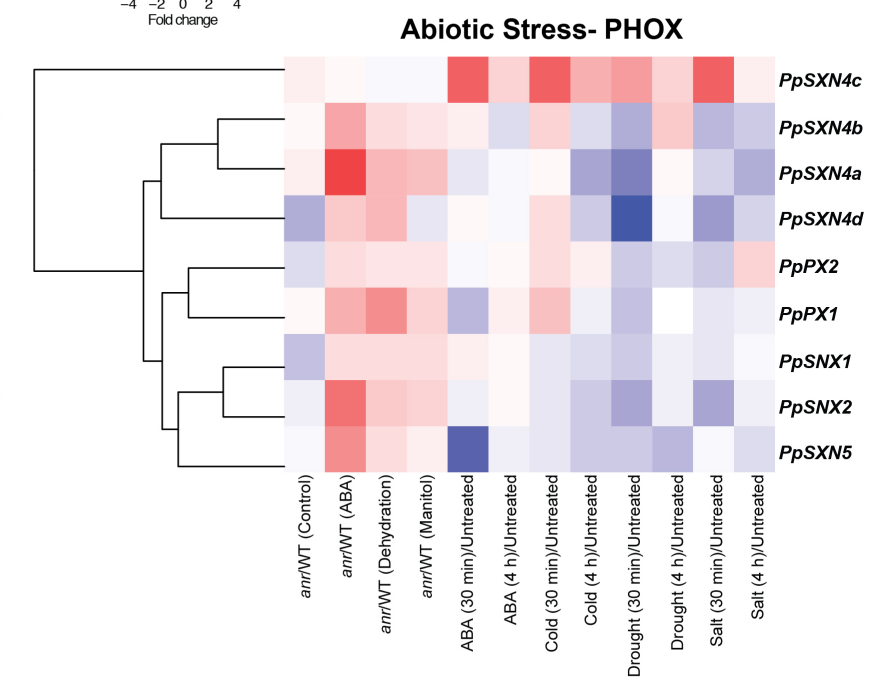


bioRxiv preprint doi: https://doi.org/10.1101/765594; this version posted September 11, 2019. The copyright holder for this preprint (which was not certified by peer review) is the author/funder, who has granted bioRxiv a license to display the preprint in perpetuity. It is made available under aCC-BY-NC-ND 4.0 International license.

\section{Figure S1}

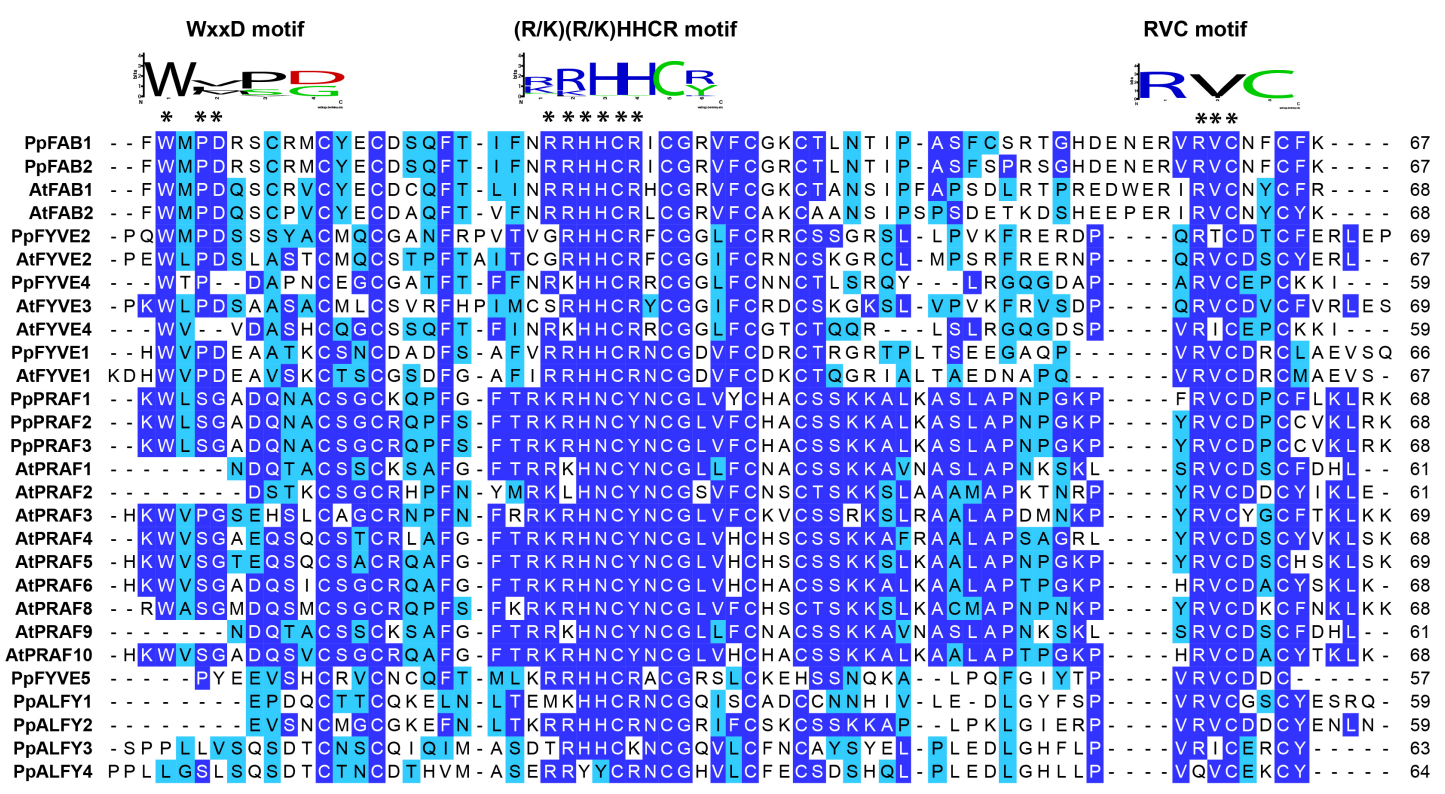


bioRxiv preprint doi: https://doi.org/10.1101/765594; this version posted September 11, 2019. The copyright holder for this preprint (which was not certified by peer review) is the author/funder, who has granted bioRxiv a license to display the preprint in perpetuity. It is made available under aCC-BY-NC-ND 4.0 International license.

\section{Figure S2}

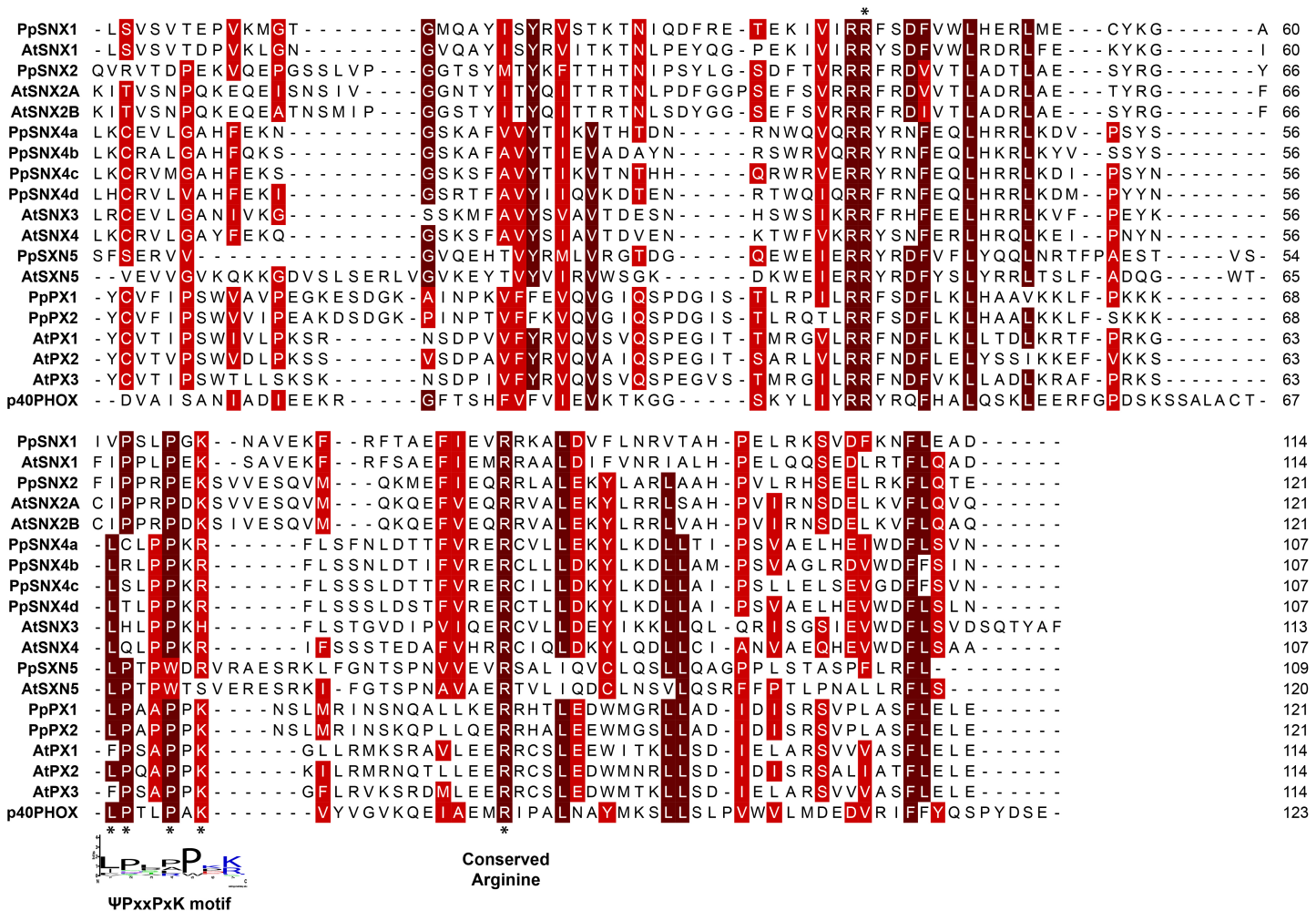


bioRxiv preprint doi: https://doi.org/10.1101/765594; this version posted September 11, 2019. The copyright holder for this preprint (which was not certified by peer review) is the author/funder, who has granted bioRxiv a license to display the preprint in perpetuity. It is made available under aCC-BY-NC-ND 4.0 International license.

\section{Figure S3}

A

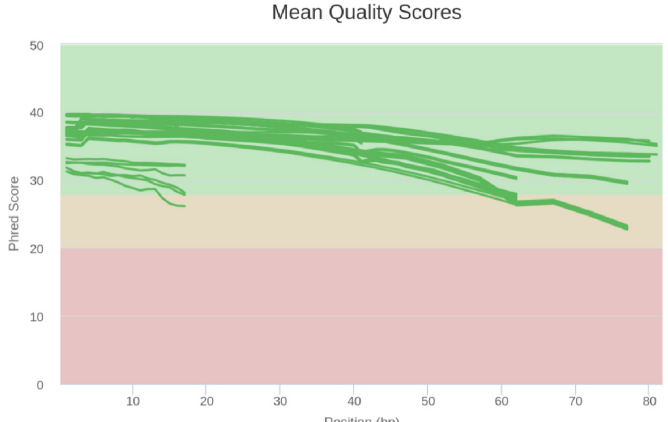

B

Length of the reads

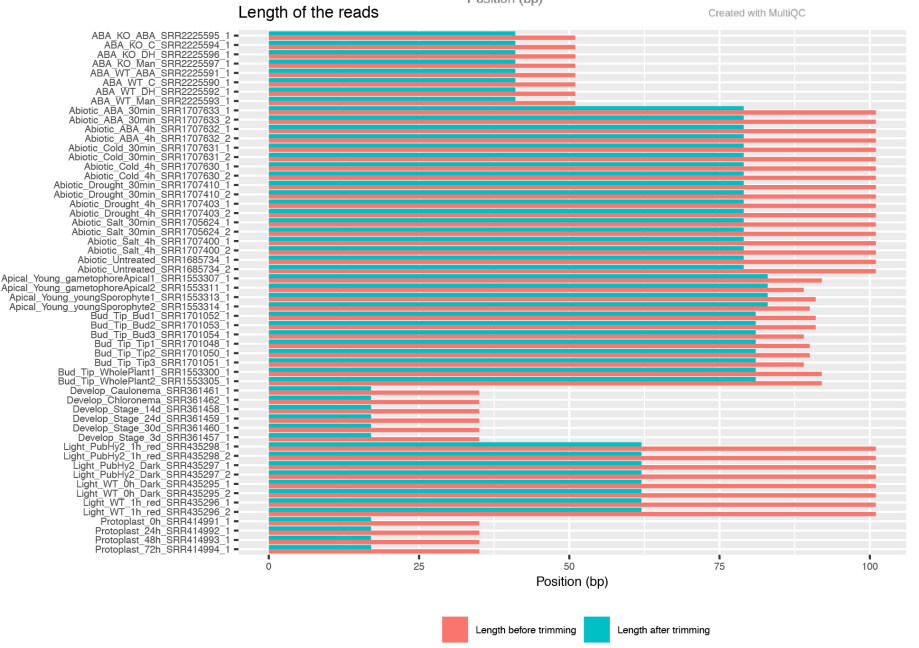

C

Number of reads

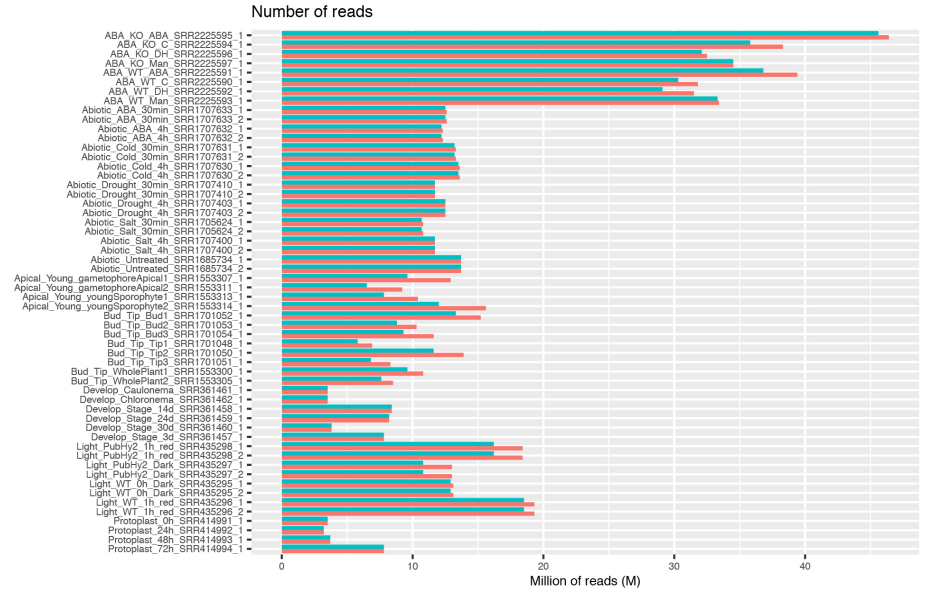

D

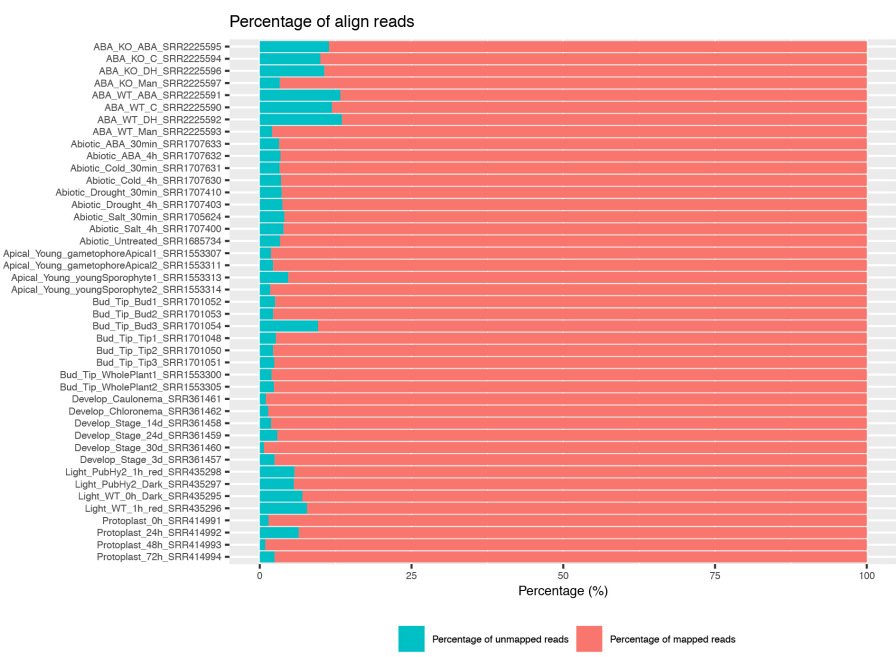

